\title{
From the apron into the pit: the deposition of the complete debris from the manufacture of a bifacial preform at the Middle Paleolithic site of Kabazi V, level III/4-2
}

\author{
Thorsten Uthmeier ${ }^{1}$ • Victor P. Chabai ${ }^{2}$ - Andrey P. Veselsky ${ }^{2}$ \\ Received: 25 July 2019 / Accepted: 28 November 2019 / Published online: 14 February 2020 \\ (C) The Author(s) 2020
}

\begin{abstract}
At Kabazi V, level III/4-2, the entire debris from the manufacture of a bifacial preform was found deposited in a small anthropogenic pit. The bifacial preform itself was missing. The fact that it was possible to refit all larger blanks, as well as several chips, from the pit, whereas refits with artifacts discarded on the surface of the corresponding archeological level were not found, underlines the character of the pit's contents as a closed find sensu stricto. The only explanation for the presence of chips of very small size from the same nodule, alongside the larger ones, in the pit fill is the use of an apron to collect all detached items during the process of flaking. Among the numerous anthropogenic pits from the Crimean Middle Paleolithic, the one found at Kabazi V, level III/4-2, and two other examples from Zaskalanya V and Zaskalnaya VI stand out for the intentional deposition of carefully selected artifacts in them. The sizes of the pits match the volumes of the artifacts deposited, which emphasizes the close relationship between the construction of the pits and the artifacts' deposition. This article explores the significance of the three cases of artifact deposition referred to above to our understanding of segmented production processes and of why these depositions occurred. The most evident interpretation is that they were caches of equipment stored as insurance for unforeseen circumstances, which is indicative of substantial planning depth and a recurrent use of logistical territories.
\end{abstract}

Keywords Crimean Middle Paleolithic $\cdot$ Anthropogenic pits · Deposition oflithic artifacts $\cdot$ Cache $\cdot$ Hideout $\cdot$ Symbolic behavior . Waste disposal

\section{Introduction}

At Kabazi V, level III/4-2, a small anthropogenic pit close to the back wall of the rock shelter was found to contain the entire debris resulting from the manufacture of a Middle Paleolithic bifacial preform. Refitting the outer part of the original raw nodule allowed us to reconstruct the cast of the

This article is part of the Topical Collection on Is 'Neanderthal behaviour' a useful concept?

Thorsten Uthmeier

thorsten.uthmeier@fau.de

1 Institut für Ur- und Frühgeschichte, Department Alte Welt und Asiatische Kulturen, Friedrich-Alexander Universität Erlangen-Nürnberg (FAU), Kochstrasse 4/18, 91054 Erlangen, Germany

2 Institute of Archaeology, National Academy of Sciences of Ukraine, Heroes of Stalingrad Avenue 12, Kiev 04210, Ukraine preform, which was not found in the pit or in the assemblage from the corresponding archeological level (Veselsky 2008a). Typologically and technologically, the refit and the cast belong to the Crimean Micoquian (Chabai 2004a; Chabai 2004b; Chabai 2007; Chabai and Uthmeier 2006; Chabai and Uthmeier 2018), which is in many aspects similar to the Central and Eastern European Micoquian (Bosinski 1967; Veil et al. 1994; Richter 1997; Jöris 2001; Pastoors 2001; Schild 2005; Picin 2016; Wiśniewski et al. 2019). Compared to the overall archeological record, more or less complete refits are rare in the Paleolithic and are mainly confined to core reduction sequences; the Middle Paleolithic cores from Maastricht-Belvedere (Roebroeks 1988; de Loecker 2006) and the Upper Paleolithic pieces arquées from Etiolles (Pigeot 1987) are well-known examples. For bifacial reduction sequences, completeness comparable to that evidenced in the Kabazi V find has only been described at the Solutrean site of Les Maîtreaux (Aubry et al. 2003a). While the technological aspects have already been described in detail (Veselsky 2008a), research has yet to elucidate any other aspects of the 
refit's context. It is beyond doubt that the selection and deposition of the small assemblage recovered from the pit were intentional in nature, but the conceptual context of that deposition has remained unclear to date. Possible hypotheses range from the supposition of a deposition on a local and situational scale to a purely functional end, such as waste management, to proposals linking the deposition to subsistence tactics, anticipation of future needs and planning, as in the case of caching, or symbolic purposes. This article's principal objectives are to formulate a testable hypothesis of potential intentions and to identify that or those most evidently explaining the data collected from the pit.

Reports of the intentional deposition of Paleolithic artifacts mainly stem from the Upper and Final Paleolithic of Europe (Peresani 2009) and Northern America (Huckell and Kilby 2014; Kilby 2018), but also from Asia (Tabarev et al. 2013). Verporte 2012) lists several caches consisting of bone and antler points from the Central European Aurignacian. At Geißenklösterle (Hahn 1988) and Vogelherd (Hahn 1986), the storage of semi-finished bone and ivory points is combined with the storage of leather or hides and faunal raw material such as antler and ivory; the large bulk of perishable materials stockpiled in these latter instances points to seasonal gear stored for a planned return in the near future. A functional purpose is also assumed for the caches of half-products for Solutrean leaf points at Montaud, La Guitière, and Monte da Fainha (Aubry et al. 2003a). For most examples from the Magdalenian and the Federmessergruppen listed by Peresani (2009), the fact that the artifact depositions contained varying numbers of unworked or tested raw pieces, preforms, and/or larger numbers of blanks supports the argument that the depositions served as stocks of raw material. Artifact depositions with various contents are a characteristic feature of the Northern American Paleoindian industries, where they are most numerous in the context of Clovis (Huckell and Kilby 2014). In most cases, the assumption is that they were stocks of insurance gear, but some are considered to have had a nonutilitarian function (Kilby 2018). Research has similarly advanced, among others, an interpretation involving ritual purposes for the late Paleolithic site of Tolbor in Mongolia (Tabarev et al. 2013). This deposition of 57 large flakes of the same raw material was found in an isolated geographical position between two major river valleys. The ritual character of the deposition of 15 finished Solutrean laurel leaf points at Volgu (e.g., Aubry et al. 2003b) is less clear, but some authors consider the artifacts' deposition to relate to the symbolic representation of their makers' technical skill (Kilby 2018).

When it comes to distinguishing between functional and ritual depositions, one of the first issues we face lies in the ambiguous character of the deposited items and the uncertainty of their reuse. The spatially clustered depositions of perforated molluscan shells as in the Aurignacian site of Grotta di Fumane (Broglio et al. 2005) and the Badegoulian site of
Wiesbaden-Igstadt (Terberger 1994, 1998) provide perhaps one of the most impressive illustrations of this dilemma. Despite the fact that the shells themselves may have had a non-utilitarian aspect, at least some of them were almost certainly attached to clothes or other parts of everyday equipment made from leather (Wolf and Conard 2018). Therefore, as an alternative to a ritual interpretation, we might consider the shell depositions as functional, and the shells as seasonally collected objects connected to the temporarily interrupted manufacture of clothes. Similar uncertainties occur in the case of the boomerang from Obłazowa Cave (Valde-Nowak et al. 1987), whose primary interpretation identifies it as a burial gift in the context of a secondary burial, but which may also have been a seasonally cached item unrelated to the human finger bone found in the vicinity. In contrast to the numerous examples from the Upper Paleolithic, Middle Paleolithic artifact depositions are rare. The few examples of caching of lithic implements we have from this period come from the Grotte Vaufrey (Rigaud 1988; Geneste 1985, cf. Peresani 2009), and Zaskalanya V and VI (Kolosov 1983; Kolosov 1986; Chabai and Veselsky 2007), where bifacial tools and flakes were deposited in anthropogenic pits. At Tönchesberg, a clustered concentration of antlers was interpreted as a cache for an anticipated return to the site (Conard 1992).

The intentional deposition of artifacts for foreseen or unforeseen future activities clearly implies planning depth, as does the spatial and temporal fragmentation of reduction sequences, for which there is good evidence at numerous European sites as early as the Middle Paleolithic (Turq et al. 2013). Transformation analyses of raw material units at numerous sites from the Crimean Middle Paleolithic (Chabai et al. 2005, 2006, $2007,2008)$ show the presence of this phenomenon in the Crimean Middle Paleolithic, where workpieces at all stages of manufacture, including raw pieces and tested nodules, were transported from site to site (Chabai and Uthmeier 2006, pp. 336-341). Taking into account distances from raw material sources, it becomes evident that bifacial tools were transported over longer distances than were cores (Chabai and Uthmeier 2006, figs. $18-20$ to $18-22$ ), an observation also made in other studies (Turq et al. 2013). The almost complete refit of the debris from the manufacture of a bifacial preform found in a pit at Kabazi V, level III/4-2, enables us to consider the purpose behind the deposition of this artifact, alongside shedding light on the context of the fragmentation of bifacial flaking sequences.

\section{Material and methods}

\section{The site: Kabazi V and the Crimean Middle Paleolithic}

Kabazi V $\left(44^{\circ} 84^{\prime} \mathrm{N} ; 34^{\circ} 03^{\prime} \mathrm{E}\right)$ is a buried rock shelter situated $360 \mathrm{~m}$ above sea level in the second, internal ridge 
of the mountainous zone to the south of the Crimean Peninsula (Fig. 1). In the course of the global reduction in sea levels during the last glacial after MIS 5, the water level of the Black Sea fell by a minimum of 70 to $80 \mathrm{~m}$ until it reached the level of the drain to the Marmara Sea and thus became detached from the Mediterranean Sea (Dodonov et al. 2000; Ryan et al. 2003). During warmer interstadials, the water level may have been lower still due to evaporation. The Black Sea became a freshwater lake in its upper part and the Crimea part of the Eastern European steppe zone. The mountainous zone consists of three ridges. The main ridge arises along the southern bank to an average altitude of $1000 \mathrm{~m}$ above sea level and consists of Triassic and Jurassic flysch overlain by marine clays, continental deposits, and reef limestones (Ferring 1998, p. 25). The second, internal ridge is formed of Cretaceous and Eocene limestones and is markedly lower than the main ridge. Between Simferopol and Belogorsk, uplift and erosion formed several series of cuestas oriented southwest to northeast. The cuesta belt has a length of $70 \mathrm{~km}$, a width of 5 to $10 \mathrm{~km}$, and elevations ranging from 200 to $700 \mathrm{~m}$ above sea level. The exposure of hard and soft rocks to weathering favored the formation of numerous rock shelters at the cliff edge of the cuestas. The third, external ridge of the Crimean Mountains is a series of eroded cuesta cliffs with an

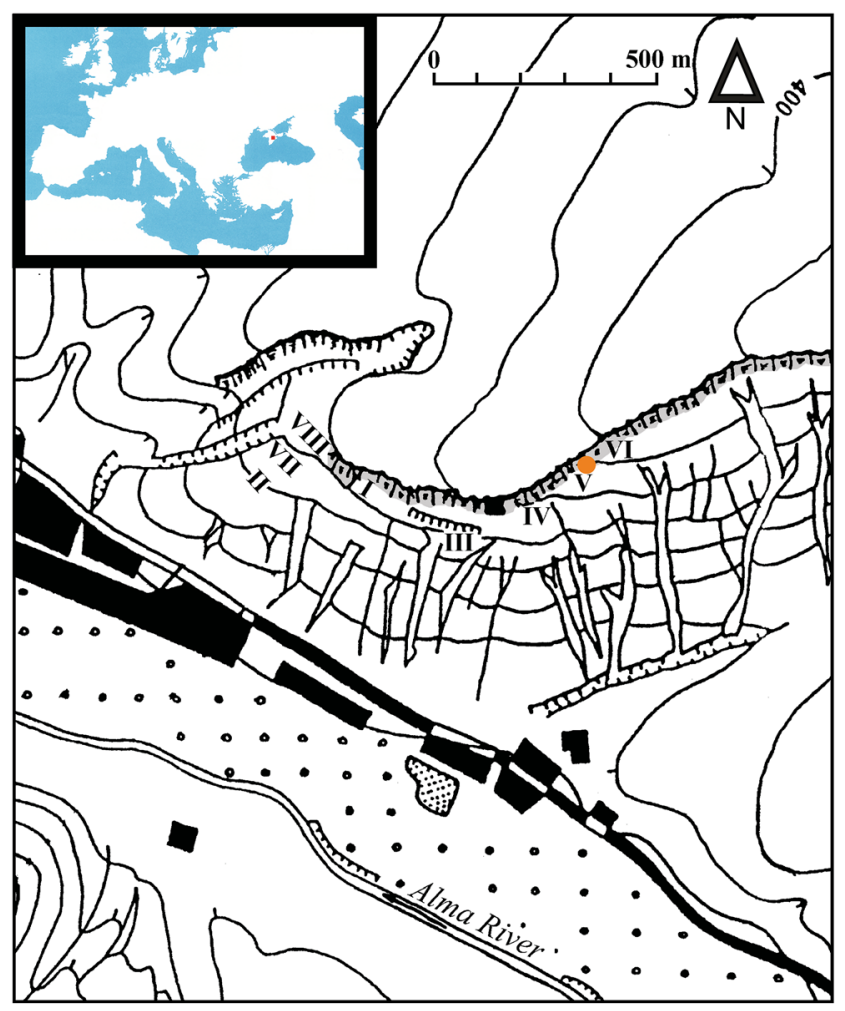

Fig. 1 Middle Paleolithic sites at Kabazi Mountain, Crimea. The orange dot shows the location of Kabazi V. Roman numerals indicate Middle Paleolithic sites along the cuesta cliff (buried rock shelters: Kabazi I and Kabazi VIII; open-air site: Kabazi II; concentrations of surface material: Kabazi III, IV, VI, and VII) (modified after Chabai 2008a, Fig. 1-1) average elevation of less than $200 \mathrm{~m}$ above sea level. Approximately 100 Middle Paleolithic sites are known. Almost all of the 31 stratified Middle Paleolithic sites identified thus far are rock shelters situated in cliffs of cuestas of lower elevation, found in the internal ridge of the Crimean Mountains (Chabai and Uthmeier 2006; Uthmeier and Chabai 2010). It is not in doubt that most of this bias stems from factors impeding or facilitating discovery; whereas thick sediments cover potential Paleolithic sites in the steppe zone, the visibility of the rock shelters in the cuesta cliffs encouraged early research to concentrate on these settings. Later research also included surveys for buried rock shelters, but the general strategy of focusing on the densely scattered area of finds on the internal ridge of the Crimean Mountains remains essentially in place to this day.

This notwithstanding, the lower part of the Crimean Mountains' internal ridge includes ecotones which would doubtless have been attractive to hunter-gatherer communities seeking subsistence. Most sites have access to the southern fringes of the steppe zone, the cuesta plateaus, and the deeply incised river valleys within a 4-h walk, that is, within a day's round trip from a camp (Uthmeier et al. 2008). The variability of the relief leads to a mosaic of vegetation cover and thus to higher biodiversity and biomass compared to flatter landscapes (Sauer 2018). The higher amount of prey present in the locality, the good availability of other essential resources such as water and firewood, and the many topographic situations suitable for a variety of hunting techniques appear as major archeological reasons for the concentration of Middle Paleolithic sites along the cuestas of the internal ridge. Supporting these assumptions, there is evidence of intensive use of these sites from both a synchronic (find density within the archeological levels) and a diachronic perspective (number of archeological levels at a given site) (Chabai and Uthmeier 2006; Uthmeier and Chabai 2010). Further, the existence of residential camps, on the one hand, and functionally corresponding kill and butchering sites, on the other, combined with the stability of site use throughout the associated stratigraphies, points to at least seasonally established logistical subsistence patterns. Summarizing, we may safely assume that Middle Paleolithic hunter-gatherer groups regularly surveyed the cuestas in the internal ridge for food resources and spent most of the warm season there.

The area around Kabazi Mountain is only one example indicating the significance to Middle Paleolithic subsistence of the lower elevations of the Crimean Mountains' internal ridge. Kabazi Mountain is part of a line of cuestas some $13 \mathrm{~km}$ southwest of Simferopol. The presence here of two key Crimean Middle Paleolithic sites, the kill and butchering open-air site of Kabazi II (Chabai et al. 2005, 2006) and the residential camp at the Kabazi V rock shelter (Chabai et al. 2007, 2008), is indicative of this micro-region's intensive diachronic Middle Paleolithic use. In addition, its western and 
northern slopes encompass more than 20 localities where Middle Paleolithic surface material is present. The Kabazi V rock shelter is elevated about $110 \mathrm{~m}$ above today's river valley and is located only $500 \mathrm{~m}$ from Kabazi II as the crow flies, on the same cuesta cliff.

\section{The archeological level: Kabazi V, level III/4-2}

Kabazi V was excavated by Y. Kolosov in 1986 (Kolosov et al. 1993), by A. Yevtushenko from 1993 to 1996 (Yevtushenko 1998a, 1998b) and by V. Chabai in 1990, 2002 and 2003 (Chabai et al. 2007; Chabai et al. 2008). A series of monographs and several separate articles contain detailed accounts of the site formation process, the lithic and faunal assemblages found, environmental studies, and various approaches to its absolute dating (Chabai et al. 2007, 2008; Chabai and PatouMathis 2006; Uthmeier and Chabai 2018); this article will accordingly restrict itself to giving a brief summary. The 8-mthick sequence consists of 27 lithological layers containing 40 archeological levels. The excavated area of $56 \mathrm{~m}^{2}$ (Fig. 2) runs parallel to the known part of the former rock shelter's back wall and represents only part of the area available during Middle Paleolithic occupations (Uthmeier and Chabai 2018). Each of the three excavation periods referenced above produced different, yet increasing stratigraphic resolutions. Level III/4-2 was only recognized in the part of the site excavated during the last two field campaigns, headed by Chabai et al. (2007). Within the site formation process of the rock shelter, level III/4-2 pertains to a phase in which the roofed part was certainly larger than the excavation trench. The presence of bats and hibernating bears suggests that the excavated area was protected from daylight and thus at some distance from the dripline. Slope erosion observed in the opposite direction of the back wall toward the south nevertheless points to the proximity of the opening to the excavated area and the presence of a relatively small platform. Level III/4-2 was found in sediments of lithological layer 12lower, which originates from the gelifraction of the rock shelter walls and roof. Level III/4-2 is part of several excavation units (levels III/4-6 to III/4-1) that were difficult to separate (Uthmeier and Chabai 2018, pp. 12-13). While sterile sediment or flat limestones permitted the identification of an ancient surface in some areas, it was difficult and sometimes impossible to follow the natural surfaces in other parts. In these cases, differentiation of archeological levels is based on assumptions applying known depths from the better-preserved parts. AMS dates are assumed to be more reliable than those produced via other dating methods (Housley et al. 2007), which gave contradictory dates for the uppermost part of the rock shelter fill. Two radiocarbon dates were obtained for Kabazi V, level III/4-2. One sample of charred bone was the humic acid fraction and gave an uncalibrated date of (OxA-X-2134-45) 30,980 $\pm 220 \mathrm{BP}$, which we need to interpret as a minimum age only in light of the less rigorous chemical treatment applied. A second date of
(OxA-14726) 38,780 $\pm 360 \mathrm{BP}$ or, if calibrated, $43,138 \pm 602$ calBP (Uthmeier and Chabai 2018, Fig. 11) acquired on charcoal is presumably reliable.

\section{Excavation methods}

Whenever possible, excavations at Kabazi $\mathrm{V}$ followed natural surfaces (Chabai 1998), taking threedimensional measurements of, and mapping, the positions of artifacts and faunal remains larger than $5 \mathrm{~cm}$ and of significantly sized stones. The sediments were excavated by square meters and dry- and wet-sieved. Lithological layers (which we will refer to henceforth as "layers") were defined by changes in color, grain size, the inclination of stones, etc. and labeled using Arabic numerals (e.g., layer 12). "Units" refers to the labeling of stratigraphic units during excavations directed by Kolosov; these are indicated by Roman numerals (e.g., Unit III). Their sole significance is to facilitate comparison and correlation between older excavations and those conducted later; in the course of more recent field campaigns, Chabai identified numerous archeological levels in the originally defined "cultural layers." Archeological levels (referred to henceforth as "levels") were identified by color, e.g., content of charcoal, ash, and soot, combined with the presence of an artifact scatter. The labeling of archeological levels combined the denomination of Units of former excavations with that of the number of levels detected in that Unit (e.g., level III/4). In cases where differentiating archeological levels was difficult, with distinctions based on defined removals of sediment rather than natural surfaces, the labeling indicated this subdivision using hyphens (e.g., level III/4-2). The excavation of pits followed a twofold strategy, distinguishing distinct levels within the fill alongside creating a minimum of one profile by excavating different parts of the fill one after another. At the same time, the lower surface of the feature was excavated following its negative form.

\section{Refitting and analysis of lithic artifacts}

It became apparent that artifacts from the pit at square 9AA in level III/4-2 showed very similar attributes in terms of their raw material. Subsequently, the team prioritized searching for refits within the lithics from the fill of the pit, before proceeding to attempt refits of artifacts from archeological level III/42 . The end product of the debitage and bifacial façonnage was found neither in the pit nor in the excavation area. The completeness of the refit enabled the team to reconstruct the missing inner part of the flaked nodule by filling it with a paraffin-based wax. The resulting cast possessed almost all negatives of the bifacial artifact and permitted 


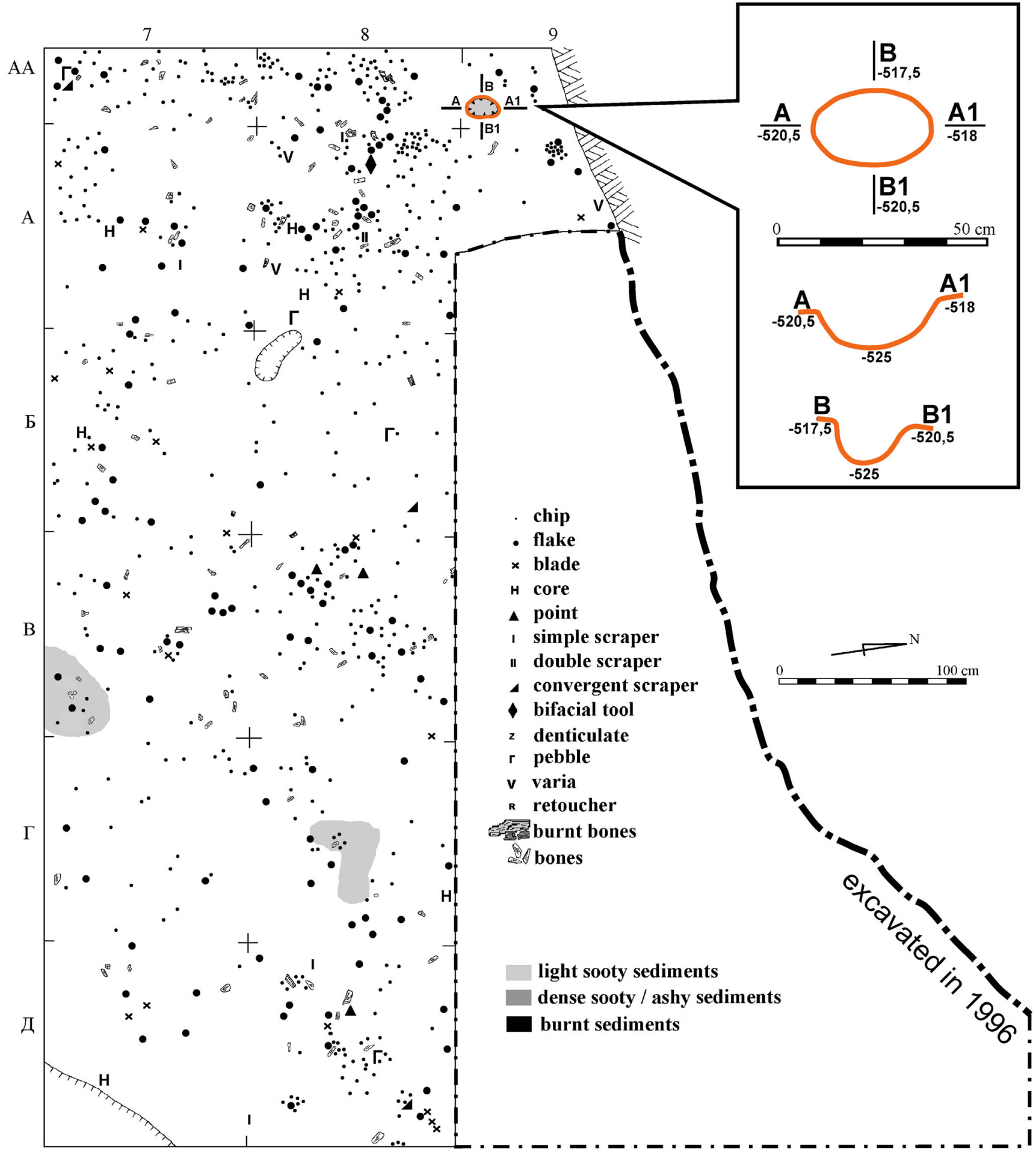

Fig. 2 Kabazi V, level III/4-2. Map of the surface excavated in 2002 and 2003. The anthropogenic pit (circled orange) was found in square 9AA; the profiles of the pit are given on the right of the map; the dashed line

typological classification (Veselsky 2008a). All artifacts were classified in accordance with the system proposed by Chabai and Demidenko (1998) and underwent an attribute analysis using these systematics. Publications elsewhere have detailed the technological aspects of the refit and the indicates the limits of the excavation area of 1996 (modified after Chabai and Veselsky 2007, Figs. 2-10 and 2-12)

results of the techno-typological analysis conducted on the entire assemblage (Veselsky 2008a, 2008b). This article therefore references only existing data from the lithic analysis and compares the sub-assemblage from the pit with the artifacts found in the corresponding archeological level. 
Table 1 Interpretation of features in the Crimean Middle Paleolithic (following Chabai and Veselsky 2008) and the different stages of post-depositional disturbance experienced by them

\begin{tabular}{|c|c|c|c|c|c|}
\hline & In situ hearth & Party disturbed hearth & $\begin{array}{l}\text { Redeposited } \\
\text { burnt material }\end{array}$ & Pit & Erosional depression \\
\hline Horizontal boundary of feature & Well defined & & Scattered & \multicolumn{2}{|l|}{ Well defined } \\
\hline Shape in top view & Ovoid or round & $\begin{array}{l}\text { Irregular with a tail of light } \\
\text { gray colored sooty } \\
\text { sediments extending to } 1 \\
\text { or } 2 \text { directions }\end{array}$ & $\begin{array}{l}\text { Light gray color } \\
\text { scatter } \\
\text { reminiscent of } \\
\text { the tail areas }\end{array}$ & \multicolumn{2}{|l|}{ Ovoid or round } \\
\hline Shape in profile(s) & Flat & & & $\begin{array}{l}\text { At minimum } \\
3 \text { more or } \\
\text { less abrupt } \\
\text { walls }\end{array}$ & $\begin{array}{l}\text { Slightly sloping/shallow walls; if } \\
\text { present, abrupt wall is situated to } \\
\text { the side the slope gradient is at its } \\
\text { highest }\end{array}$ \\
\hline Sediment & $\begin{array}{l}\text { High content of } \\
\text { soot/ash }\end{array}$ & Low content of soot/ash & $\begin{array}{l}\text { Very low } \\
\text { content of } \\
\text { soot }\end{array}$ & \multirow{3}{*}{\multicolumn{2}{|c|}{$\begin{array}{l}\text { Sediment filling/other components/stratigraphical } \\
\text { sequence depending on anthropogenic use } \\
\text { and/or post-depositional site formation process- } \\
\text { es }\end{array}$}} \\
\hline Other components & Burnt bones and & artifacts & $\begin{array}{l}\text { Burnt bones and } \\
\text { artifacts }\end{array}$ & & \\
\hline Micro-stratigraphical sequence & $\begin{array}{l}\text { Ash } / \text { sot occasion } \\
\text { whitish calcite }\end{array}$ & $\begin{array}{l}\text { ally intercalated with beds of } \\
\text { ash }\end{array}$ & None & & \\
\hline Sediments below & $\begin{array}{l}\text { Crust of yellow- } \\
\text { ments }\end{array}$ & red to red-brown burnt sedi- & $\begin{array}{l}\text { No burnt } \\
\text { sediment }\end{array}$ & \multicolumn{2}{|c|}{$\begin{array}{l}\text { If used as fireplace: crusts of yellow-red to } \\
\text { red-brown sediments }\end{array}$} \\
\hline $\begin{array}{l}\text { Relation between the size of the } \\
\text { area with burnt sediment and } \\
\text { the concentration of ash/soot } \\
\text { below }\end{array}$ & Identical & $\begin{array}{l}\text { Burnt sediment below } \\
\text { smaller than } \\
\text { concentration of ash/soot }\end{array}$ & Not applicable & \multicolumn{2}{|c|}{ If used as fireplace: identical } \\
\hline
\end{tabular}

\section{Identification of evident structures}

Pits and hearths have been described at a number of Crimean Middle Paleolithic sites, including Starosele, Shaitan Koba, Kabazi I, Kabazi II, Kholodnaya Balka, Chokurcha I, Volchi Grotto, Kiik Koba, Zaskalnaya V, Zaskalnaya VI, Prolom I, and Prolom II (Ernst 1934; Bonch-Osmolowski 1940; Formozov 1958, Formozov 1959a, b; Chernysh 1965; Liubin 1969, 1970; Kolosov 1972, 1979, 1983, 1986; Bader and Bader 1979; Marks et al. 1998; Chabai 2004a; Chabai and Veselsky 2007; Chabai and Uthmeier 2018). The comparably high frequency of such features has enabled the development of a detailed set of attributes for differentiating between natural depressions and anthropogenic pits and identifying their use by humans (Table 1). Most fills of anthropogenic pits evidently resulted from trampling and/or natural post-depositional processes caused by lowenergy run-off of surface water. In cases where the dissolution of the Tertiary nummulitic limestone led to a fine-grained, soft matrix, it is not entirely clear whether depressed features, and their fills, resulted from natural processes or are of anthropogenic origin (cf. Uthmeier and Chabai 2018 regarding an example at Zaskalanya V). In other cases, ample evidence attests to the use of pits and natural depressions as fireplaces in the Crimean Middle Paleolithic. By contrast, only in three cases have anthropogenic pits served as receptacles for the deposition of artifacts (Chabai and Veselsky 2007). The key to distinguishing between anthropogenic pits and natural depressions appears to lie in the configuration of the feature's walls. It is only the presence of abrupt walls of at least three quadrants of a pit that suggests anthropogenic origin. Sloping walls, conversely, indicate that natural processes have contributed to varying extent to the genesis of a depression, depending on the number of quadrants showing such a profile.

\section{Interpretation of artifact depositions}

This article uses the neutral term "deposition" to refer to the activity of deliberately placing objects in a spatially restricted location with the intention of restricting immediate access, thus interrupting the immediate use of the items. The term allows for a large array of interpretations with regard to the intention and function of the activity it denotes. However, some archeological researchers subsume all depositions under the term "cache" (Kilby 2018). When carried out by prehistoric hunter-gatherers, "caching" more usually refers to a behavior aiming at storing objects for future reuse (Peresani 2009), thus implying a certain remnant use of the stored items (Kilby 2018). 


\section{Estimation of the remnant use of lithic artifact depositions}

To estimate the remnant use of deposited lithic artifacts, a "remnant use index" ("RUI") was developed. It is based on the totalized average time during which the deposited lithic items could have been in use. Given the many uncertainties in estimating the duration of lithic artifacts' use, the index is not intended to give precise absolute values, but instead to permit comparison on the basis of mean values documented in experiments, ethnographic studies, and comparative analysis of larger samples of archeological finds. In general, the estimation of the potential duration of lithic tools' use depends on multiple factors difficult to control even in systematic experiments (Merritt and Peters 2019). The properties of the materials worked, the raw material of the lithic tools, tool morphometry and size, and the expertise of the tool's user all influence the efficiency of the activities performed and thus the amount of stress affecting the working edges. Most experiments therefore follow a comparative approach, investigating the relative efficiency of different tool types or tool morphometries (e.g., flakes versus bifacial surface-shaped tools or differently shaped bifacial tools) rather than giving absolute working durations to exhaustion (for an overview see Key and Lycett 2017a). A further significant factor in this context is the fact that lithic tools were often used for a variety of activities, applying different amounts of energy to different materials at varying angles, which affects absolute duration of use (Shott and Sillitoe 2005). Our preference was for the data used here to be drawn from experiments which used the handheld tools to replicate archeologically observed traces or objects rather than employing machine-based experiments. One disadvantage of experiments with human rather than machine performance is the variation in the durations of use observed; for unretouched flakes, Schick and Toth (1993, p. 166, cf. Galán and Domínguez-Rodrigo 2014, p. 1071), for instance, give a maximal use duration of 5-10 min of butchery without resharpening, whereas Galán and Domínguez-Rodrigo (2014, p. 1071) documented $60 \mathrm{~min}$. In a comparative experiment with unretouched, retouched, and hafted lithic tools, Clarkson et al. (2015) carried out a pre-defined amount of strokes to cut wood with each artifact. Even after 10,000 strokes or $100 \mathrm{~min}$ of working time, the artifacts were formally still functional, even though they were only removing minimal amounts of material by this stage. Ethnographic data (Hayden 1979; Shott and Sillitoe 2005) is indicative of a much lower duration of use until discard, of between $6 \pm 5$ and $17 \mathrm{~min}$ on average. The differences underline that subjective decision-making, intertwined with the availability of alternatives, is an influential factor in identifying the lower threshold of acceptable tool performance. At first glance, differences in the morphometry of the tools, such as mass, length of cutting edge, and/or size, also appear to be problematic. However, experiments using relatively large samples of both bifacial tools (Key and Lycett 2017b) and simple flakes (Key and Lycett 2014; Merritt and Peters 2019) came to the conclusion that these factors, above a certain minimum size threshold, do not seem to have a significant impact on the tools' efficiency. Rejuvenation is another measure for increasing the total duration of lithic objects' use and accounts for unretouched blanks, retouched blanks, and cores. Although models for enhancing the duration of lithic artifacts' use via rejuvenation exist (Clarkson et al. 2015), individual variations in raw material properties and size make it difficult to estimate precise durations of use after rejuvenation. The remnant use index is an attempt to reduce complexity in this context by making the purely theoretical assumption that the use of lithic tools involved one working edge only, and that the tools were used until the abandonment of the first working edge. The same accounts for the raw material: all data used in the remnant use index for estimating the duration of use for the artifact classes stem from experiments conducted with flint tools. The following paragraphs will discuss the principal aspects involved in calculating the remnant use index: the duration of use of unretouched flakes, retouched items, and bifacial tools, the diminishing marginal utility seen with decreasing tool size, and the remnant use of cores.

Most data on the correlation between the size of a flake and its capability for handheld cutting activities come from butchery experiments (see Merritt and Peters 2019 for a summary of the history of research in this area). Given the fact that butchery involves a variety of worked materials ranging from soft to hard tissue, as well as diverse working modes and angles, the assumption is that it provides a good comparison to the multi-functional use of many retouched items (Clarkson et al. 2015) and allows us to identify general trends in the use duration and the minimum size of lithics suitable for producing working materials. In contrast to earlier assumptions (Frison 1974), several more recent butchery experiments (Key and Lycett 2014; Merritt and Peters 2019) have shown that, in general, the influence of tool size, e.g., the length of the cutting edge and/or the mass of the lithic item, on cutting efficiency is not as straightforward as previously thought. A decrease in efficiency only resulted where size, mass, and/or the morphometry of a tool fell below or above a certain threshold. With regard to the lower threshold for size, it emerged out that even small flakes were suitable for butchering and, although less effective in cutting, produced even faster disarticulation times compared to larger flakes. From a practical point of view, it nevertheless seems clear that the minimum size of lithic tools suitable for handheld cutting is limited by both the length of the cutting edge and a sufficiently large prehensile part. Although use wear has attested the use of small chips for cutting small portions of fresh meat in the Acheulo-Yabrudian of Qesem (Lemorini et al. 2014), cutting experiments (Prasciunas 2007) with harder materials reported a drop in efficiency below a surface area of $7 \mathrm{~cm}^{2}$. Recent large-scale experiments (Key and Lycett 2014; Merritt and Peters 2019, p. 228) with a controlled variety of movements and worked materials did not use flakes 
smaller than $27 \mathrm{~mm}$ in length. Jennings et al. (2010, p. 2159, cf. Pastoors et al. 2015) give a similar minimum value of $>25 \mathrm{~mm}$ for "useful flakes." Consequently, chips (defined as unretouched items smaller than $3 \mathrm{~cm}$ ) are not included in the calculation of the remnant use index.

Surprisingly, experiments conducted by Clarkson et al. (2015) have shown that unretouched flakes can be significantly more effective than retouched flakes, at least in the case of woodworking. However, when Clarkson et al. modeled the optimal moment for changing a tool and included the investment of time for its manufacture (Clarkson et al. 2015, Fig. 7.6), unretouched flakes gave the best return rate until 6 min of use, whereas retouched flakes lasted $10 \mathrm{~min}$. Despite this better overall performance (Clarkson et al. 2015, Fig. 7.4), unretouched flakes quickly experienced a significant drop in cutting efficiency. The higher investment of time in their production meant it was optimal to change the less effective retouched flakes at a later point. The remnant use index employs this data due principally to their good fit with ethnographic studies (Clarkson et al. 2015, p. 128). For the sake of compatibility, the estimation of the duration of bifacial tools' use is also based on experiments in woodworking, Veil (1990a; 1990b) reports that while manufacturing a replica of the Middle Paleolithic spear from Lehringen, the use duration of a typical Middle Paleolithic handaxe was recorded at 98 min (Veil 1990a). However, this included several stages of work and the resharpening of one of the lateral edges. No rejuvenation was documented for the initial cutting of a small tree. We therefore use a working time of $45 \mathrm{~min}$ to calculate the use duration of a bifacial tool (without rejuvenation).

The estimation of cores' remnant use employed data collected by Pastoors et al. (2015) in the course of work step analysis of 271 cores, differentiated by the concept of core reduction employed, from 14 Middle Paleolithic assemblages found in Central and Southwestern Europe. In a first step, the relative frequencies of the technologically differentiated negatives per core for each assemblage given in the original data were transformed into natural numbers. The next step involved calculating the mean number of negatives per core. From this data, bar charts (Fig. 3) were produced with the software PAST Version 3.26 (Hammer et al. 2001) for cores reduced via the Levallois concept and by the discoid method as well as for all cores. For each calculation, a differentiation between negatives of predetermined flakes, predetermined and predetermining flakes, predetermining flakes, and all flakes was made (for more information on the defining criteria for negative types, see Pastoors et al. 2015). Considering only flakes with predetermined outline and thickness (Fig. 3: A and B), the cores reduced by the discoid method (Fig. 3(3): median $=6.9$ flakes per core) are more productive than cores reduced via the Levallois concept (Fig. 3(2): median $=3.3$ flakes per core). The differences are less significant for all negatives per core (Fig. 3(2-3): D). After the suggestion emerged from recent experimental data that the influence of the morphometry of handheld flakes on their efficiency in cutting is low (Key and Lycett 2014; Merritt and Peters 2019), it would seem fair to calculate the remnant use index using the median of the average of all negatives per core. In the Crimean Middle Paleolithic (Chabai 1998, 2004a; Chabai and Uthmeier 2006; Bataille 2017), there is ample evidence for the use of the Levallois concept in the Crimean Mousterian. Blank production in the Crimean Micoquian is based on simple cores with centripetal removals from one major flaking surface and the use of flakes from surface shaping. The core reduction of the Crimean Micoquian is not fully compatible with the discoid method; however, due to the fact that the work step analysis estimates the last negatives rather than the total output of the core reduction, we can nevertheless take it as a proxy for the efficiency of Crimean Micoquian core reduction. To estimate the remnant use of cores discarded in the Crimean Middle Paleolithic, we multiply the median of the average number of all negatives per core, without differentiating by reduction concept (Fig. 3(1): D), by the estimated use duration for unretouched flakes. In contrast to cores, bifacial preforms and bifacial tools are not considered a source of flake blanks. Despite exceptions such as the microliths from Buran Kaya III, level C (Monigal 2004; Bataille 2017) and retouched chips from Buran Kaya III, level B (Uthmeier 2013), flakes from surface shaping used during the Crimean Middle Paleolithic mainly stem from early phases of production in which it is difficult to distinguish with certainty between cores and bifacial preforms; such pieces are usually classified as undetermined preform. True bifacial preforms, by contrast, lack only the final trimming and lateral retouch. During these stages, the negatives on the bifacial preforms rarely exceed the size of chips.

For a given deposition, the values for duration of use for each category are multiplied by the frequency of items. The variation in the potential for use as well as in the workload of production of each specific item (e.g., flakes versus bifacial tools) led us to take the route of adding up the results and then calculating an average by dividing the sum by the number of items. The result is given to two decimal places. In light of the many uncertainties discussed above, the approach presented here is best understood as a broad estimation of potential remnant use on the basis of averaged data from archeological experiments and ethnographic case studies.

\section{Possible function of artifact depositions among hunter-gatherers}

Figure 4 gives an overview of the terminology relating to the different forms of depositions of lithic artifacts referenced in this article. The archeological record certainly yields instances of the deposition of items that lack a clear anticipation of reuse, leading to their interpretation as waste. Most accepted examples of the deposition of waste originate from Upper 

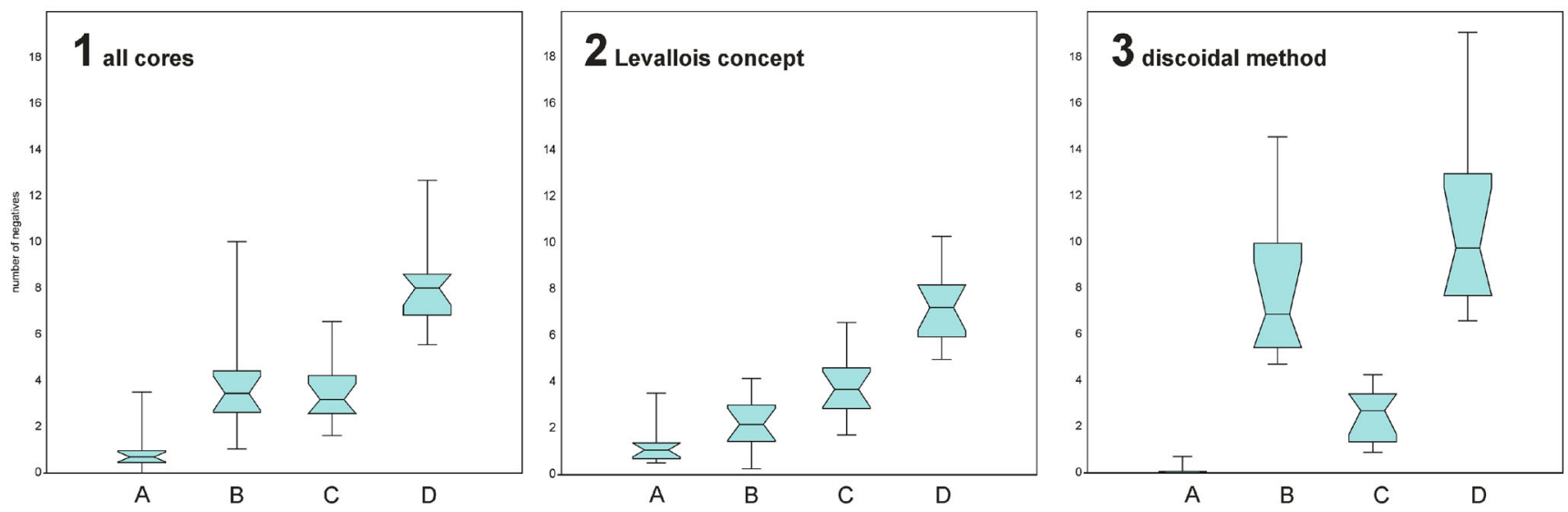

\begin{tabular}{|r|c|c|c|c|c|c|}
\cline { 2 - 7 } \multicolumn{1}{c|}{} & A predetermined & $\begin{array}{c}\text { B predetermined } \\
\text { and predetermining }\end{array}$ & C predetermining & $\begin{array}{c}\text { D all negatives per } \\
\text { core }\end{array}$ & N cores & N negatives \\
\hline discoidal method & 0.0 & 6.9 & 2.7 & 9.8 & 55 & 537 \\
\hline Levallois concept & 1.1 & 2.2 & 3.7 & 7.2 & 216 & 1,617 \\
\hline all concepts & $\mathbf{0 . 7}$ & $\mathbf{3 . 5}$ & $\mathbf{3 . 2}$ & $\mathbf{8 . 0}$ & $\mathbf{2 7 1}$ & $\mathbf{2 , 1 5 4}$ \\
\hline
\end{tabular}

Fig. 3 Box plot of the average number of flake negatives per core at 14 late Middle Paleolithic sites, differentiated by concepts and flake type (calculations by the authors on the basis of data from Pastoors et al.
2015). The box is drawn for the $25-75 \%$ quartiles of each sample, with the median shown as a horizontal line inside the box; short horizontal lines represent the minimum and maximum values

low value. In addition, the deposits may be hidden or marked, while the deposition itself may have proceeded secretly by individuals or in public. Another issue is the exceptionality of the act itself, which separates it from everyday activities and implies a temporal interruption of or insertion between ritual activities of the same kind. The assumption among archeologists is that the formalized and repetitive character of ritual behavior generates recognizable traces in the archeological record. The only instances of supposed Paleolithic ritual depositions that were not burials relate to topographically isolated depositions of selected objects with high remnant use and high work-intensive production process (as in the case of Volgu: Kilby 2018), making such objects rare to unique in the synchronous archeological record (Tabarev et al. 2013).

"Caching" is the deposition of objects in anticipation of their reuse (Binford 1978). Ethnographic case studies have reported caches as including objects with long-term storage lives as well as perishable materials such as antler, firewood, and meat. However, most data from the Paleolithic record is restricted to lithic materials. It is evident in theory a decision to create or not create a cache is multifactorial (Peresani 2009). Among other factors, it may include the general degree of the specific group's mobility - that is, the frequency with which the group moves and resettles and the distances it covers doing so-, the degree of anticipation of future activities, the size and weight of the gear to be transported and therefore the effort of transportation, and the remnant use. Other associated matters relate to the spatial placement of caches in terms both of the distance between the place of acquisition and that of storage and of the dane objects as well as exceptional ones, and items of high and 
logistical subsistence-settlement system

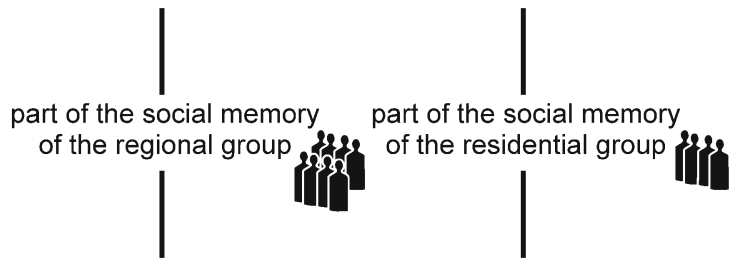

measures to secure/facilitate retrieval, e.g. surficial marking, use of natural features, transfer of information to others etc.

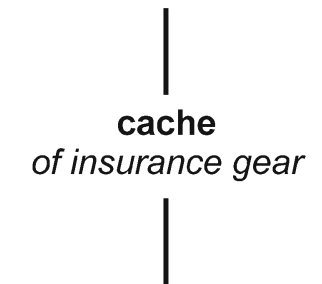

return to the site or locale not presicely planned, but considered possible
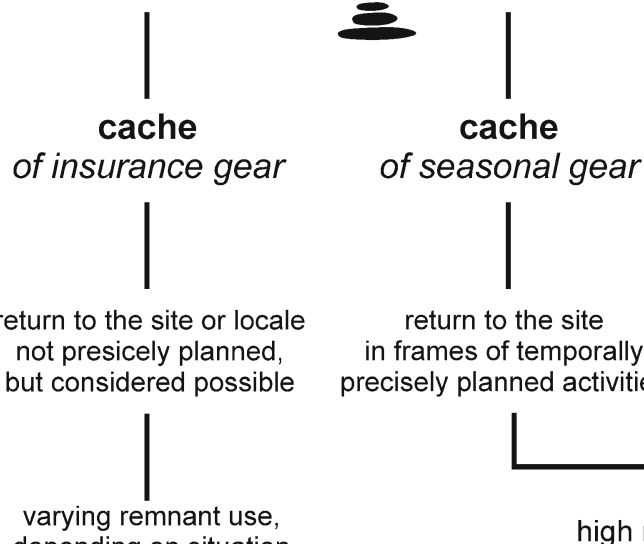

depending on situation in frames of temporally
precisely planned activities

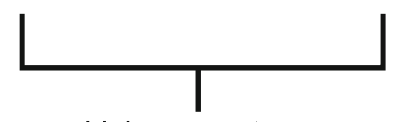

high remnant use independent from subsistence-settlement system
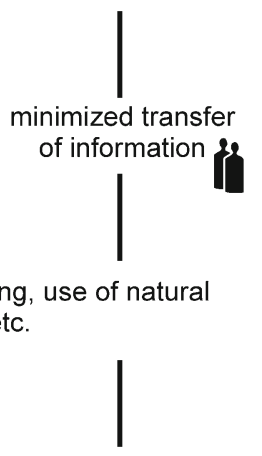

hideout

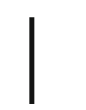

future return to the site planned under more secure circumstances

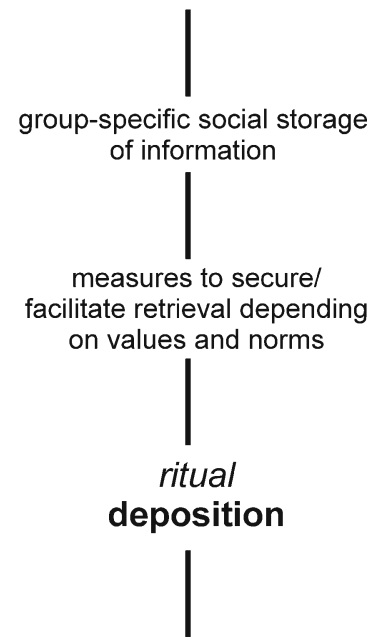

return (and re-use?) depending on specific values and norms

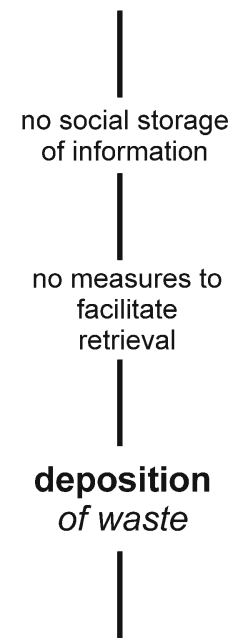

potential return to the site unrelated to deposition activity

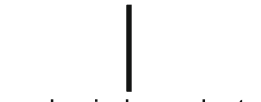

value independent from remnant use
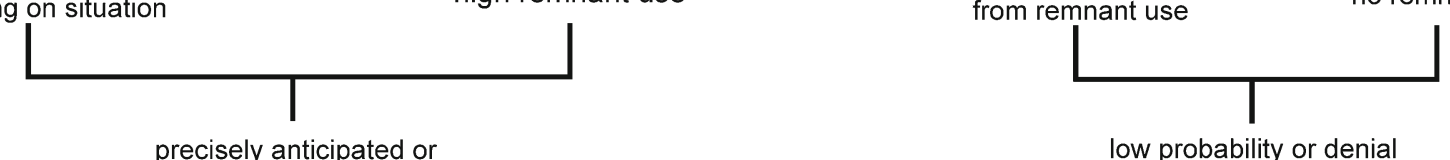

low probability or denial generally anticiapted re-use

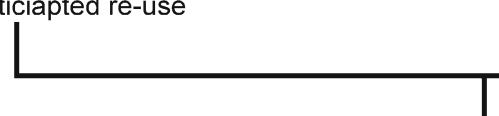

of re-use

Intentional, spatially clustered deposition in a covered feature to restrain immediate access

Fig. 4 Possible functions of intentionally deposited items (see text for detailed explanations)

configuration of the landscape that facilitates successful retrieval. From a functional point of view, we can assume that the existence of caches is related to the technological organization of sites in the context of logistical subsistence tactics (Peresani 2009).

\section{Contextualizing artifact depositions}

Analysis of the context of the deposition from Kabazi V, level III/4-2, proceeds at a variety of spatial scales. On the level of the evident feature itself, the analysis aims at identifying anthropogenic acts that form short-term coherent sequences and have simultaneously contributed to the construction and filling of the pit. A Harris matrix enables visualization of the temporal sequence in which these acts will have taken place. In exploring the local context of the find, we analyzed the placement of the pit in relation to natural structures such as the back wall, other features, and/or potential areas of human activity. The spatial analysis drew on the detailed mapping of formal tools, unmodified lithic tools, sooty areas, and evident features from the excavations in 2002 and 2003. In addition, the deposition at Kabazi V, level III/4-2, was compared to similar features from the Crimean Middle Paleolithic.

\section{Results}

\section{Site formation processes in level III/4-2}

Level III/4-2 is 1 to $2 \mathrm{~cm}$ thick and embedded in stratigraphic sub-unit III/4 at the base of lithological layer 12lower (Chabai 2007). During excavations, the identification of occupation surfaces was difficult because no continuous sterile sediments were observable in the 10-cm-thick unit. As a consequence, we attempted to identify occupation surfaces by the occurrence of sooty concentrations and the presence of limestone boulders, assuming that the base of the boulder indicates the ancient floor. While this worked on a small scale, the restricted size of these features complicated the tracking of the recognized surface in the surroundings. In addition, all six 
archeological levels defined during the excavations showed an increasing gradient both north to south and west to east, that is, toward the slope in front of the rock shelter, which favored post-depositional processes. These processes included the run-off of surface water, but the dynamics must have been rather low due to the high frequency of chips, the presence of soot, and the good preservation of fauna (Fig. 2). While it is beyond doubt that the pit in square 9AA and its fill are in situ, any relationship to artifacts recovered from the surrounding surface of the pit is uncertain. This point is of some significance here, as one aspect when considering the probable function of the deposition is anticipated reuse, which would require a group presumably returning to the site within a short period. In better-preserved levels at Kabazi V, it is indeed possible to argue for such a scenario. For example, in level III/2 of Kabazi V, it was possible to distinguish two spatially separated occupations on the same surface thanks to differences in the preservation of the faunal remains around two fireplaces found in separate parts of the excavation area (Chabai and Patou-Mathis 2006). The two concentrations of faunal remains correlate with different seasons of the year and to the hunting of different species and thus represent two distinct occupations on the same surface. This, admittedly nonrepresentative, example underlines the probability that even the levels of the multilayered Crimean Middle Paleolithic sites, often only 2-5 cm thick (Chabai and Uthmeier 2006), reveal recurrent site use rather than single episodes. Due to the considerable degree of consistency in the site setting and the environmental context along the sequence of Kabazi V (Uthmeier and Chabai 2018), this also applies to the assemblages from Unit III. In sum, it is vital to treat the lithic assemblage from level III/4-2 as a "cumulative palimpsest" (Bailey 2007) of different occupations within a short time span, affected by post-depositional processes (Uthmeier and Chabai 2018, Fig. 10), and to take this into consideration when discussing the overall lithic assemblage; indeed, in this context, caution is of the essence whenever we refer to lithic artifact data from level III/4-2.

\section{Artifact distribution and evident features in level III/4-2}

Detailed documentation of the distribution of the lithic artifacts, evident features, and limestone blocks is available for the 2002-2003 excavations only (Fig. 2). The continuation of the back wall of the rock shelter to the north was excavated in 1996 (Chabai and Veselsky 2007, Fig. 2-10). Subsequent to processes of erosion, the uppermost part of the cuesta cliff today features semi-circular, short gullies with radii of approximately 5 to $25 \mathrm{~m}$ that rest upon layers of harder limestone. It is in one of these curves that the rock shelter was formed. It is conceivable that the roofed area ended to the west in the curved back wall, which was in that particular part identical to the present-day cuesta cliff. This is of particular interest because the position of the pit in square 9AA is both near the excavated northern part of the back wall and close to its unexcavated western corner. The effect of post-depositional processes means we can regard the sooty areas in square $7 \mathrm{~B}$ and $8 \Gamma$ as no more than evidence of the nearby presence of one or more fireplaces of unknown exact spatial and chronological position. This is still more the case due to the fact that burnt sediments, which are a better spatial proxy for fireplaces, were not observed in level III/4-2. Post-depositional processes also prevent detailed analysis of the lithic find scatters. This also accounts for the higher find density in the northwestern area near the back wall. With regard to the increasing slope of the surface toward the south and the east, one may assume that the less inclined northwestern area is the better preserved part of the paleosurface and simultaneously the source of at least part of the materials found in the sink area toward the dripline. If this assumption is correct, the pit in square 9AA was situated in a part of the rock shelter that offered a more or less horizontal floor and was therefore attractive for human occupation. Even if post-depositional processes have removed part of the finds from the excavation area - which is in doubt due to the high frequency of chips - then overall find density would still be low, pointing to less intensive occupation.

\section{The evident feature of pit 9AA}

During the uncovering of the artifact scatter of level III/4-2, an ovoid area of densely packed artifacts in square meter 9AA was recognized and classified as a small pit (Fig. 5a). The feature was excavated by carefully removing the fill in two segments to obtain a cross-section (Fig. 5b). However, the excavation identified no stratigraphic discontinuity, which indicates that the pit was filled in rapidly. The filling comprised a total of 2786 artifacts mixed with small amounts of sediment identical to that of lithological layer 12lower, which were found in the gaps in between the lithics. Scattered in the sediment of the filling were 16 small bone splinters, one of which was burnt. The original shape of the pit was visible after the removal of the filling (Fig. 5c). At the upper edge, the pit was ovoid in shape and measured $29 \mathrm{~cm}$ in length and $18 \mathrm{~cm}$ in width (Fig. 2). At the rounded bottom, the pit was $7 \mathrm{~cm}$ deep. The shape of the bottom and the semi-abrupt walls support an anthropogenic origin of the pit. The pit's rounded cross-section leaves open the possibility that the pit was dug into the soft sediment without using a sharp and/or wide tool. The correlation between the size of the pit and the volume of the artifacts deposited in it argues persuasively for a direct link between the two. It is evident that the pit was dug exclusively to cache the artifacts instead of reusing an existing pit. It is highly probable, albeit not establishable with absolute certainty, that the pit and its filling belong to the same occupation surface as the artifacts found in other parts of level III/4-2. There is no indication that 
the pit was dug from an occupation surface other than that pertaining to the discarded artifacts of the remaining assemblage. The uppermost artifacts of the filling were not separated from level III/4-2 by a sterile level, nor were they found at a different depth. Of course, this only means they were contemporaneous in a sedimentological sense; the palimpsest character of the assemblage renders us unable to specify the exact chronological relationship between the pit filling and the discard of the remaining assemblage from the level, which in itself presumably represents more than one occupation. The bone splinters in the filling suggest that, at the time of the artifacts' deposition in the pit, faunal remains were lying on the surface of level III/4-2. The single burnt bone splinter points to the existence of a fireplace. Again, the fact that post-depositional processes were active in that level lessens this observation's informational value. The presence of the bone splinters may nevertheless be indicative of activities (fireplace, butchering) near the pit and related to the same occupation, or earlier ones. Given that the area around the pit was the source rather than the sink of post-depositional processes, it is unconvincing to surmise that the bone splinters were redeposited and therefore totally unrelated to the pit.

\section{The refit of artifacts deposited in pit 9AA}

Veselsky (2008a, 2008b) has provided detailed accounts of both the refit and the assemblage from pit 9AA. The majority of the 2786 lithic artifacts are chips (Table 2), with larger blanks accounting for less than $2 \%$. It was possible to refit the entirety of the artifacts larger than $3 \mathrm{~cm}$, that is, 51 flakes and blades, which are the primary constituents of the refit (Figs. 6 and 7). The total number of refitted artifacts is 105, which is $2.98 \%$ of the artifacts from the pit filling. Eightythree of the refits conjoined ventral and dorsal surfaces, and in 22 cases, fragments of broken items were refitted. It has to be stressed that refits were only possible between artifacts from pit 9AA, but not between artifacts from the pit and those from level III/4-2. Due to the small size of the items, it was not possible to refit more than $1.17 \%$ of the chips in an appropriate amount of time. Nevertheless, there is no doubt that these also stem from the reduction of the refitted sequence. Even without the cast of the preform retained by filling the empty core of the refit with paraffin wax (Fig. 8), we can class the refit as representing a bifacial reduction conducted with a soft hammer. Arguments for the unity of all artifacts from pit 9AA are as follows: (1) their having been found in the filling of the pit, (2) the matching raw material attributes, and (3) the matching technological attributes (e.g., more than $50 \%$ of the chips have a lipped platform). Both the refitted and non-refitted artifacts from the pit originate from early phases of the manufacture of a bifacial tool and comprise the decortication of the round and flat flint nodule and the initial phase of surface shaping; the high frequency of artifacts with cortex on the dorsal surfaces (Fig. 9) is indicative of this. No less than 29 artifacts have cortical cover of over $75 \%$, whereas the number of those with cortical cover below $25 \%$ is a negligible 2 pieces. The refits represent a continuous reduction of the partly decorticated raw nodule. One side of the refit in particular (Fig. 6, side 1) lacks approximately half the cortical surface, which gives rise to the assumption that part of the initial flaking took place outside the excavated area and presumably at another site (Veselsky 2008b). Likewise, the refit does not represent the final thinning of the bifacial tool, of which, judging from the size of the refitted artifacts from the last detachments, there is likewise no evidence among the nonrefitted chips. Despite this, the refit still permitted us to identify the bifacial reduction concept. The fourth stage of the manufacturing process defined by Veselsky (2008b) can be classified as an alternate shaping of the preform surfaces typical of Micoquian bifacial tools, termed "wechselseitiggleichgerichtete Kantenbearbeitung" by Bosinski (1967, p. 43) or "plan convexe / plan convexe" by Boëda (1995, p. 76). Filling the inner part of the refit with an artificial wax resulted in a cast that, typologically speaking, is the preform of a bifacial scraper (Fig. 8). Comparison of the metrics of the cast and the
Fig. 5 Kabazi V, level III/4-2. Views from the southwest of the anthropogenic pit in various phases of excavation (a excavation of the upper surface; $\mathbf{b}$ cross-section; c original shape after excavation of the filling). Note the abrupt walls and the small size of the pit, which corresponds to the volume of the densely packed blanks from the manufacture of a single preform. The preform was not found in the excavated area
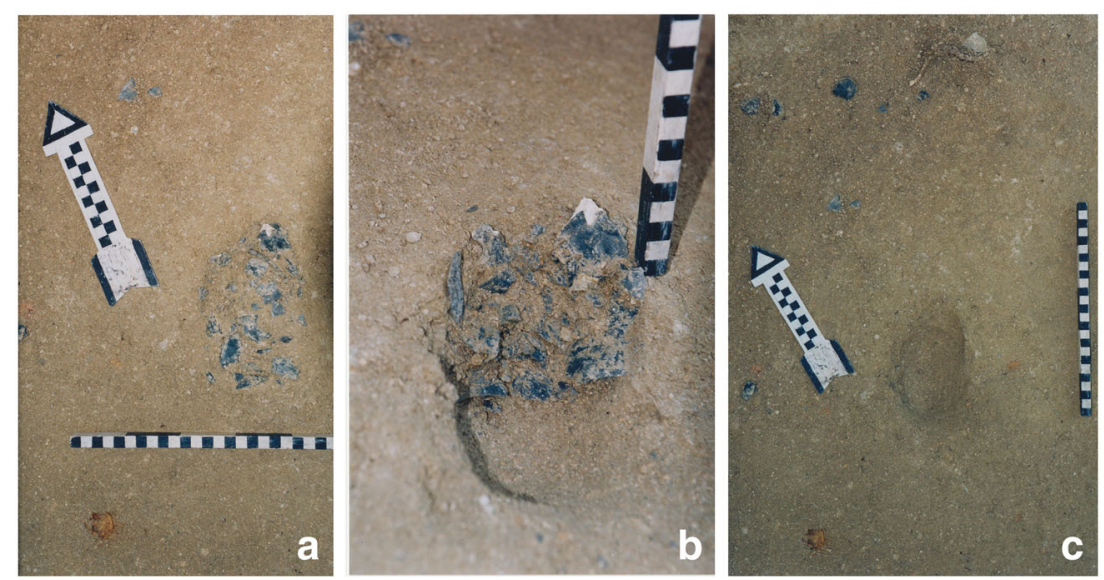
Table 2 Kabazi V, level III/4-2, pit 9AA. Blank assemblage and refitting rates (data taken from Veselsky 2008b)

\begin{tabular}{lrrrrrr}
\hline & \multicolumn{2}{l}{ Artifacts in pit 9AA } & & \multicolumn{2}{l}{ From these were refitted } & Refitting rate \\
\cline { 2 - 3 } & $N$ & $\%$ & & $N$ & $\%$ & \\
\hline Flakes & 44 & 1.58 & 44 & 53.01 & 100.00 \\
Blades & 7 & 0.25 & 7 & 8.43 & 100.00 \\
Chips & 2735 & 98.17 & 32 & 38.55 & 1.17 \\
Total & 2786 & 100.00 & 83 & 100.00 & 2.98 \\
\hline
\end{tabular}

original plaquette (Table 3) reveals an attempt to lose as little as possible of the raw piece's length. The anticipated outline of the bifacial preform was projected into the raw plaquette in such a way that it retained the maximum of the longitudinal axis. As a result, the bifacial preform virtually preserved the plaquette's original length; the original nodule is only 1.04 times longer than the preform (Veselsky 2008b). Almost all of the reduction, which in total represents approximately two-thirds of the initial

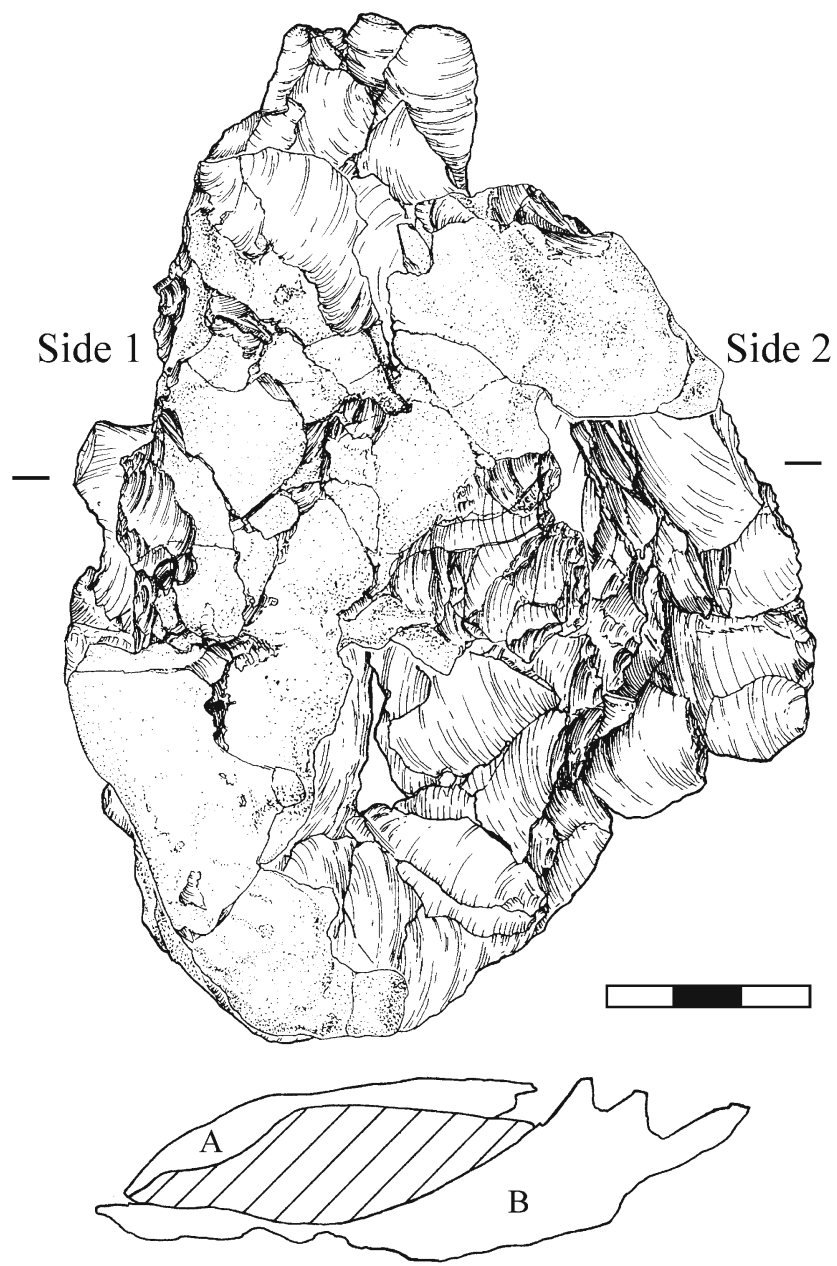

Fig. 6 Kabazi V, level III/4-2. Surface A of the flint nodule refitted from lithics intentionally deposited in pit 9AA (taken from Veselsky 2008b, Fig. 16-1)

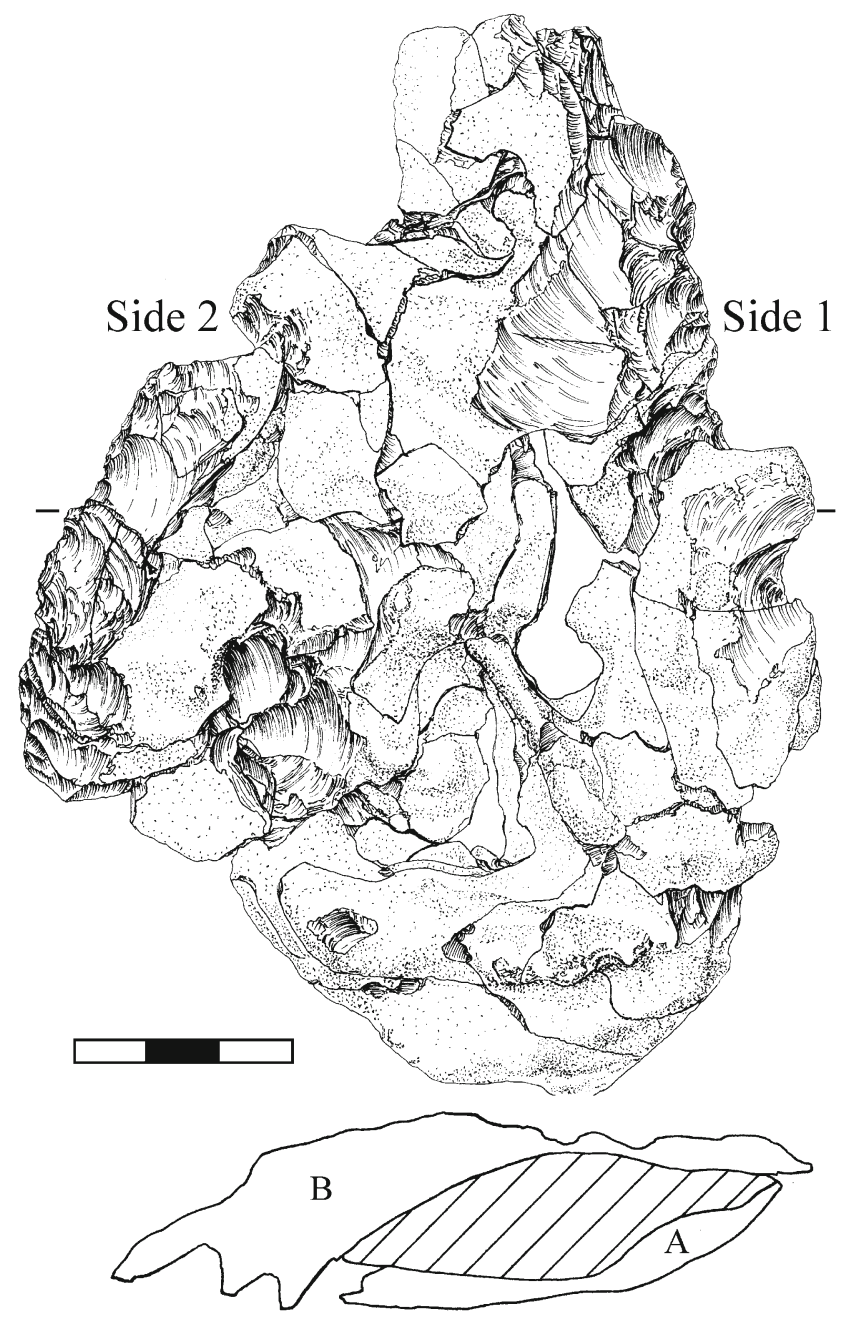

Fig. 7 Kabazi V, level III/4-2. Surface B of the flint nodule refitted from lithics intentionally deposited in pit 9AA (taken from Veselsky 2008b, Fig. 16-2)

volume, was equally restricted to the reduction of the raw piece's width and thickness.

To summarize, the artifacts from the filling of pit 9AA represent a continuous stage of the bifacial reduction of a flint plaquette resulting in the preform of a Micoquian bifacial scraper. The process of reduction was segmented in several ways. First, missing flakes from the decortication phase may suggest this took place outside the rock shelter. However, it is equally possible that larger flakes from surface shaping were put aside for modification into formal tools and therefore exported from level III/4-2 either as blanks or as tools. In general, there is plenty of evidence for the use of bifacial thinning flakes in the Crimean Middle Paleolithic (Chabai 2004a; Chabai and Uthmeier 2006; Uthmeier 2012; 2013). Second, the bifacial preform was taken out of the excavated area. Most of the lithics recovered from pit 9AA are chips and, due to their small dimensions, "static objects" (Weißmüller 1995); the probability of their having been intentionally 


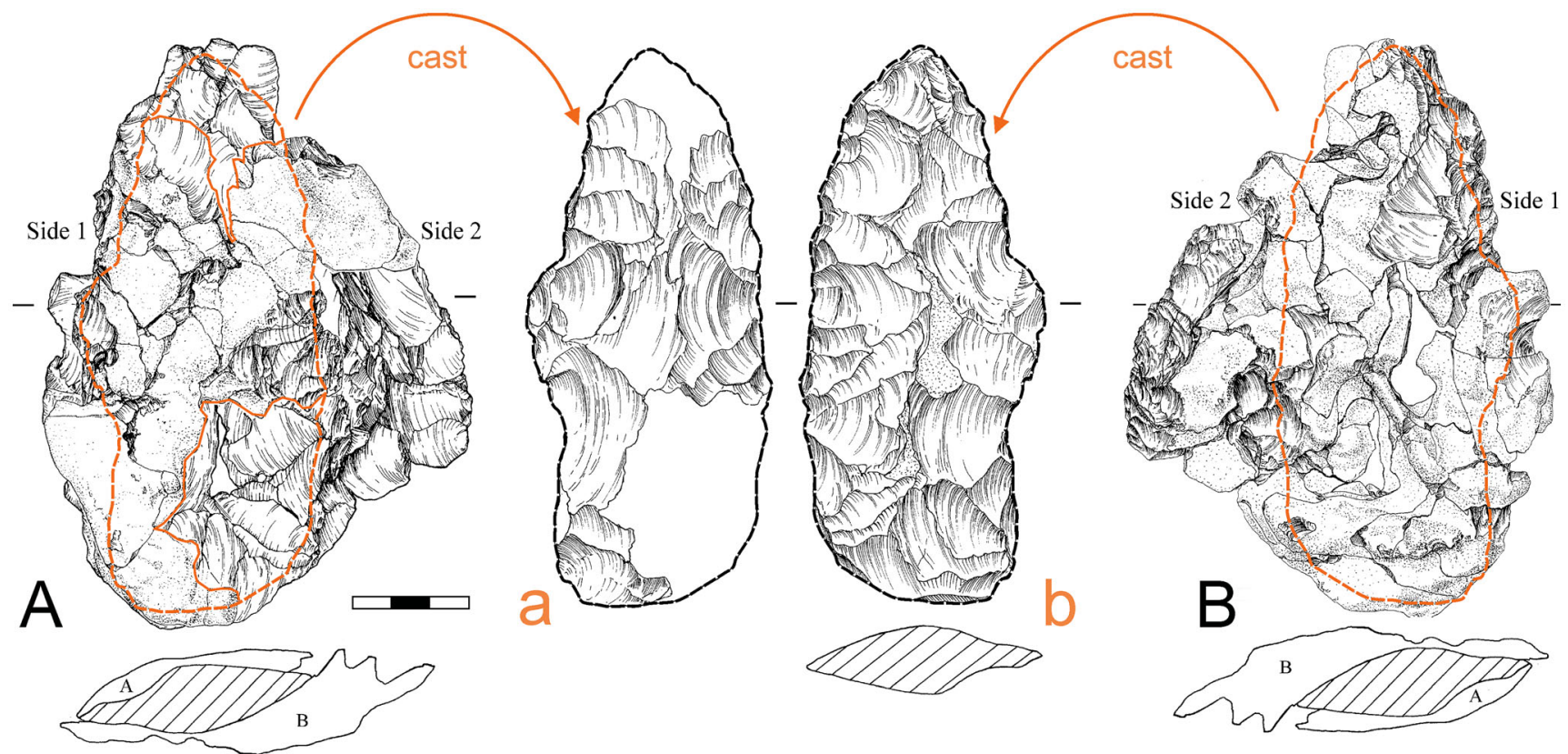

Fig. 8 Kabazi V, level III/4-2. Preform of the exported bifacial scraper, reconstructed by filling the empty inner part of the refit from pit 9AA with paraffin wax; the outline of the preform is projected onto the corresponding faces of the refitted raw nodule

moved is generally low. This said, we should not underestimate the potential value of small flakes and chips in the case of the Crimean Middle Paleolithic. At least when raw material sources were distant, as at Buran Kaya III, levels B and C, even small bifacial shaping flakes were modified (Monigal 2004; Bataille 2017). This caveat notwithstanding, for the purpose of calculating the remnant use index, the remnant use of chips is still fixed at 0 due to the threshold of

\section{cortical cover of blanks}

$(\mathrm{N}=54)$

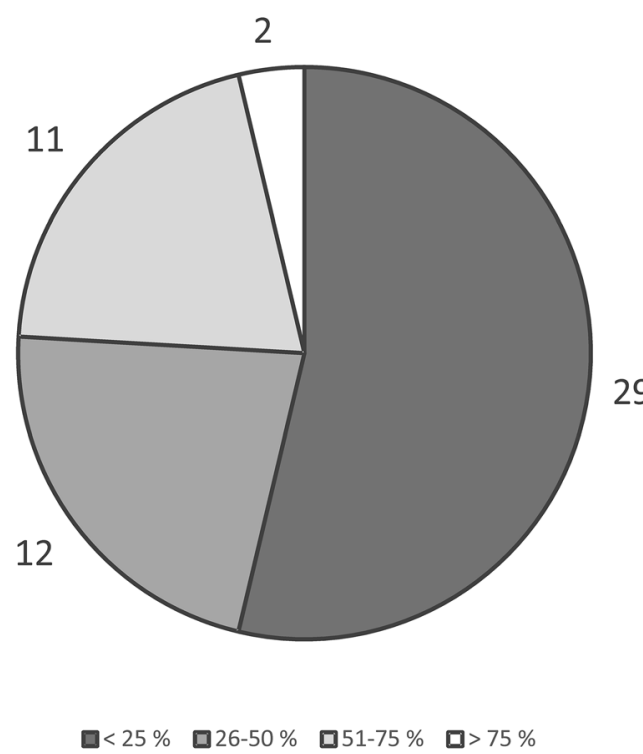

Fig. 9 Kabazi V, level III/4-2. Cortical cover of blanks $>3 \mathrm{~cm}$ recovered from pit 9AA approximately $3 \mathrm{~cm}$ as suggested in experiments and ethnographic data, for the minimum size of used flakes. The remnant use index of RUI $=6$ for artifacts larger than $3 \mathrm{~cm}$ from the pit fill is low (Table 4).

\section{The lithic and faunal assemblage from level III/4-2}

This section describes the lithic assemblage from level III/4-2 as one unit, including the lithics from pit 9AA. The primary data have already been published (Veselsky 2008a); we only summarize them here. The nearest potential sources of the lithic raw material used in level III/4-2 are the terraces of the Alma River immediately below the site, which yield flint pebbles of varying, yet inferior quality. Primary sources with large nodules of better quality are situated at Mount Milnaya, approximately $1 \mathrm{~km}$ from the site, and in the Bodrak Valley some $6 \mathrm{~km}$ away; the Bodrak is a tributary to the Alma River (Chabai and Uthmeier 2006, Fig. 1). Availability of materials must be considered good, because even the more distant, by definition "non-local" sources in the Bodrak Valley are easy to reach by following the Alma River to the southwest and then, after the confluence, walking approximately $2 \mathrm{~km}$ upstream along the Bodrak. Most of the 8131 lithic artifacts (Table 5) are chips, which account for 7930 pieces (97.6\%). Technologically, the detached blanks originate from two cores, one preform, and three bifacial artifacts. The presence of two separate modes of reduction processes is well attested (Veselsky 2008a). Typical target flakes permit us here to classify the core reduction as following the Levallois concept with recurrent unipolar target flakes, whereas bifacial tools and numerous corresponding thin blanks with characteristic 
Table 3 Kabazi V, level III/4-2, pit 9AA. Measurements of the refitted raw piece and the reconstructed preform, alongside the reduction quotient (from the raw nodule to the preform) in different directions (data taken from Veselsky 2008b)

\begin{tabular}{lcrl}
\hline & Raw piece & Preform & Reduction quotient \\
\hline Length in cm & 14.76 & 14.23 & 1.04 \\
Width in cm & 10.88 & 6.11 & 1.78 \\
Thickness in cm & 2.82 & 1.78 & 1.58 \\
Volume of the smallest circumscribing cube in $\mathrm{cm}^{3}$ & 452.86 & 154.76 & 2.93 \\
\hline
\end{tabular}

platforms and lips point to bifacial reduction. Blanks that can securely be classified as having been detached from a bifacial preform or bifacial tool represent only part of the overall debris from bifacial reduction processes, because not all of the detachment is struck using the soft hammer technique or shows all attributes of that technique. In sum, 654 chips, and flakes, or $8.05 \%$ of all artifacts, were directly associable with bifacial surface shaping (Table 5). Overall, the large number of chips underlines the intensity of flaking activities conducted on the site. Due to their small dimensions, many chips certainly originate from the preparation of striking platforms to remove flakes or blanks and from the modification of blanks into tools. Larger ones mainly stem from bifacial production. The ratio of chips to the sum of flakes and blades that experienced the preparation of their platforms and possibly also modification of the lateral edge(s) as an additional source for chips is 1:34.9 (Table 5). Taking into consideration that the class of "chips" also includes very small items, this figure seems plausible. At first glance, by contrast, the ratio of 1:30.8 between cores, preforms, and bifacial artifacts on the one hand and blanks larger $3 \mathrm{~cm}$ on the other seems rather high; two observations may serve to explain it: first, the few cores are largely reduced and of small size, measuring less than $6 \mathrm{~cm}$ in width and length; second, the manufacture of bifacial tools also produces large numbers of flakes.
Although every reduction process has individual aspects, it is still possible to obtain a quantitative estimate of the frequency of blanks in bifacial reduction by using the data from the refit of pit 9AA. The incomplete refit alone included 51 blanks larger than $3 \mathrm{~cm}$. A broader calculation puts the ratio between all artifacts from pit 9AA and the overall assemblages at 1:2.9 (Table 5), which suggests that the on-site production of three bifacial tools would be sufficient to explain this frequency of blanks. Admittedly, these calculations essentially amount to a thought experiment due to the fact that the assemblage is a palimpsest and includes the mixed blanks produced by two reduction concepts, but it may still help to calibrate the numbers. In this sense, the relationships between the frequencies of blanks give plausible figures for a technologically sound assemblage. It follows that additional variables, such as severe post-depositional processes or the export of cores or tools, are not necessary to explain the composition of the assemblage. The tool assemblage (Veselsky 2008a) comprises 45 items (Fig. 10). Scrapers dominate with 16 pieces, followed by 12 retouched pieces and 11 unifacial tool fragments. There are low numbers of other tool types: two points, two bifacial tools, one burin, and a bifacial tool fragment complete the assemblage.

This rather small assemblage, then, is characterized by the intensive reduction of a minimum of four bifacial pieces

Table 4 Estimate of the remnant use of lithic assemblages deposited in anthropogenic pits in the Crimean Middle Paleolithic on the basis of the durations of use documented in archeological experiments for each type of artifact

\begin{tabular}{|c|c|c|c|c|c|c|c|c|}
\hline & & \multirow[t]{2}{*}{$\begin{array}{l}\text { Average use time } \\
\text { in minutes }\end{array}$} & \multicolumn{2}{|c|}{$\begin{array}{l}\text { Kabazi V, level } \\
\text { III/4-2, pit 9AA }\end{array}$} & \multicolumn{2}{|c|}{$\begin{array}{l}\text { Zaskalnaya } \mathrm{V} \text {, layer } \\
\text { III, pit square } 12 Д\end{array}$} & \multicolumn{2}{|c|}{$\begin{array}{l}\text { Zaskalnaya VI, layer } \\
\text { II, pit square } 32 \mathrm{~A}\end{array}$} \\
\hline & & & $N$ & Remnant use in minutes & $N$ & Remnant use in minutes & $N \quad \mathrm{~F}$ & Remnant use in minutes \\
\hline \multirow[t]{3}{*}{ Blanks } & Unretouched flake & 6 & 51 & 306 & 84 & 504 & & \\
\hline & Retouched flake/blade & 10 & & & & & & \\
\hline & Bifacial tool & 45 & & & & & 8 & 360 \\
\hline \multirow[t]{4}{*}{ Cores } & Levallois: 7.2 flakes per core & 43.2 & & & & & & \\
\hline & Discoid: 9.8 flakes per core & 58.8 & & & & & & \\
\hline & All cores: 8.0 flakes per core & 48 & & & & & & \\
\hline & & & 6.00 & & 6.00 & & 45.00 & \\
\hline
\end{tabular}


Table 5 Kabazi V, level III/4-2. Frequency of blank types and ratios for various aspects of the assemblage (data taken from Veselsky 2008a, Tables 101 and 10-2)

\begin{tabular}{|c|c|c|c|c|}
\hline Lithic artifacts & $\mathrm{N}$ & $\%$ & $\begin{array}{l}\mathrm{N} \text { per } \\
\text { group }\end{array}$ & $\begin{array}{l}\text { \% per } \\
\text { group }\end{array}$ \\
\hline Chunk & 4 & 0.05 & & \\
\hline Preform & 1 & 0.01 & & \\
\hline Core & 2 & 0.02 & 7 & 0.09 \\
\hline Chip & 7,299 & 89.83 & & \\
\hline chip from bifacial thinning \& rejuvenation & 631 & 7.77 & 7,930 & 97.60 \\
\hline Flake & 127 & 1.56 & & \\
\hline Bifacial thinning flake & 21 & 0.26 & & \\
\hline Blade & 35 & 0.43 & & \\
\hline Bifacial thinning blade & 2 & 0.02 & 185 & 2.28 \\
\hline $\begin{array}{r}\text { Unidentifiable (bifacial tool, tool } \\
\text { fragment) }\end{array}$ & 3 & 0.04 & 3 & 0.04 \\
\hline Sub-total lithic artifacts & 8,125 & 100.00 & 8,125 & 100.00 \\
\hline $\begin{array}{r}\text { sub-total artifacts detached in the course } \\
\text { of bifacial thinning }\end{array}$ & 654 & 8.05 & & \\
\hline \multicolumn{5}{|l|}{ Pebble \& Bone Artifacts } \\
\hline $\begin{array}{r}\text { Pebbles fragment } \\
\text { bone retoucher }\end{array}$ & $\begin{array}{l}4 \\
2 \\
\end{array}$ & & & \\
\hline Sub-total pebbles and retouchers & 6 & & & \\
\hline$\underline{\text { Total }}$ & 8,131 & & & \\
\hline $\begin{array}{r}\text { ratio chips/(all blanks }>3 \mathrm{~cm}+\text { unifacial } \\
\text { tools) }\end{array}$ & \multicolumn{2}{|c|}{ 1: 34.9} & & \\
\hline $\begin{array}{r}\text { ratio (cores + preforms + bifacial tools)/all } \\
\text { blanks }>3 \mathrm{~cm}\end{array}$ & \multicolumn{2}{|c|}{ 1: 30.8} & & \\
\hline $\begin{array}{r}\text { ratio artifacts from pit } 9 \mathrm{AA}(\mathrm{N}=2.786) / \text { all } \\
\text { refitted blanks from pit } 9 \mathrm{AA}\end{array}$ & \multicolumn{2}{|c|}{ 1: 2.9} & & \\
\hline
\end{tabular}

(including the preform from pit 9AA), two cores, and one preform. Four fragmented pebbles (hammerstones) and two bone retouchers (Table 5) point to the intensity of lithic reduction having taken place. While the bifacial tools were produced from nodules, 42 were made from blanks, which equals to a modification rate of $22.70 \%$ among the detached lithics larger than $3 \mathrm{~cm}$. This comparably high value corresponds to the intensity of core reduction processes. In general, the assemblage bears attributes of the two major Middle Paleolithic industries in the Crimea (Chabai 2004a; Chabai and Uthmeier 2006), the Crimean Micoquian and the Western Crimean Mousterian. Due to the pronounced techno-typological 
Fig. 10 Kabazi V, level III/4-2. Sorted frequencies of modified pieces (data taken from Veselsky 2008a, Table 10-17)
Kabazi V, Level III/4-2

Tools $(\mathrm{N}=45)$

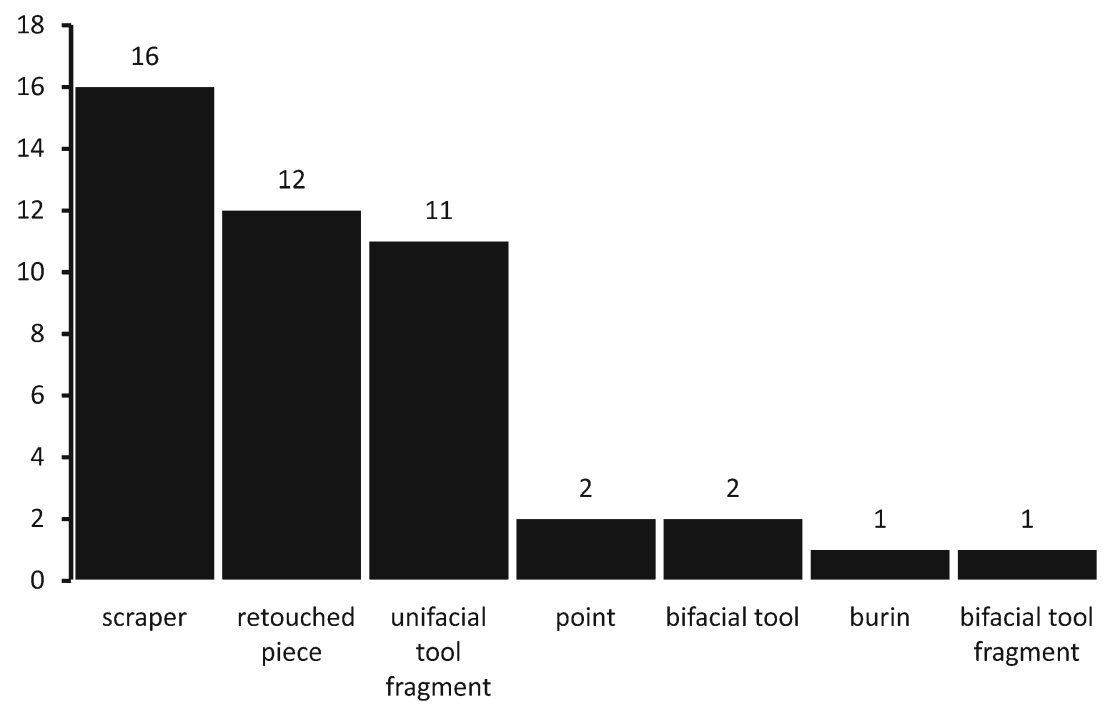

differences between the two industries, we can explain the twofold composition of the lithic assemblage from level III/ 4-2 by our finding of a palimpsest of separate occupations (Veselsky 2008a; Chabai 2007; Uthmeier and Chabai 2018).

Analysis of the faunal remains (Patou-Mathis 2007) revealed that only parts of two horses (Equus hydruntinus) and one saiga antelope (Saiga tatarica), which were dismembered and butchered elsewhere, were transported to the rock shelter. Among the skeleton elements, skull parts and lower limbs are emphatically predominant. The impact of carnivores is insignificant. The degree of anthropogenic fracture of the bones for the processing of marrow is high. It appears evident that the occupations took place during periods of nutritional stress. In the light of the body parts found, scavenging may have been one mode of their acquisition (Patou-Mathis 2007).

\section{The temporal sequence of activities related to the formation of pit 9AA}

In the usual case, assemblages from archeological levels represent a "cumulative palimpsest" (Bailey 2007). This is also the working hypothesis for level III/4-2, where the original spatial distribution was - to a different degree depending on the area of excavation - altered by natural site formation processes favored by the incline of the occupation surface. Nevertheless, the pit in square 9AA, identified as a closed find, permits us to draw some conclusions on the chronology of the corresponding anthropogenic activities and, to a much less nuanced degree, on other processes of the site's formation. The digging of the pit 9AA is certainly subsequent to the formation of the part of lithological layer 12lower which is

below the pit, as the pit itself cuts into the sediment (Fig. 11). Because the size of the pit fits exactly with the volume of the refitted artifacts, it can be concluded that the bifacial preform was manufactured before the digging of the pit. The precise relationship of these two activities to the fracturing of animal bones and the subsequent burning of part of these is uncertain. What we can say with certainty is that the totality of artifacts from the manufacture of the bifacial preform, together with some burnt and unburnt bone splinters, were later filled into the pit, and the preform exported. The use of a skin as an apron during the bifacial reduction sequence is the only plausible explanation for the completeness of the artifact filling, including chips of remarkably small size. It is not possible to state when and where the bone splinters were mixed with the artifacts. The hypothesis that most readily suggests itself is that this happened when the pit was covered by sediment; whether or not this was intentional is again impossible to establish. All that can be said about the relationship between the aforementioned steps related to pit 9AA and the remaining artifact and faunal remains from level III/4-2 is that the latter were discarded somewhere between the commencement of the occupations at the site and its final covering of the surface by sediments of lithological layer 12lower. The presence of unburnt and burnt bone splinters in the fill prove that activities related to their discard took place prior to the creation and filling of the pit. Although it seems plausible to assume that the activities around the pit were not isolated, but embedded in an occupation which included the use of a fireplace and the consumption of fauna, we cannot prove this using the data at hand. 


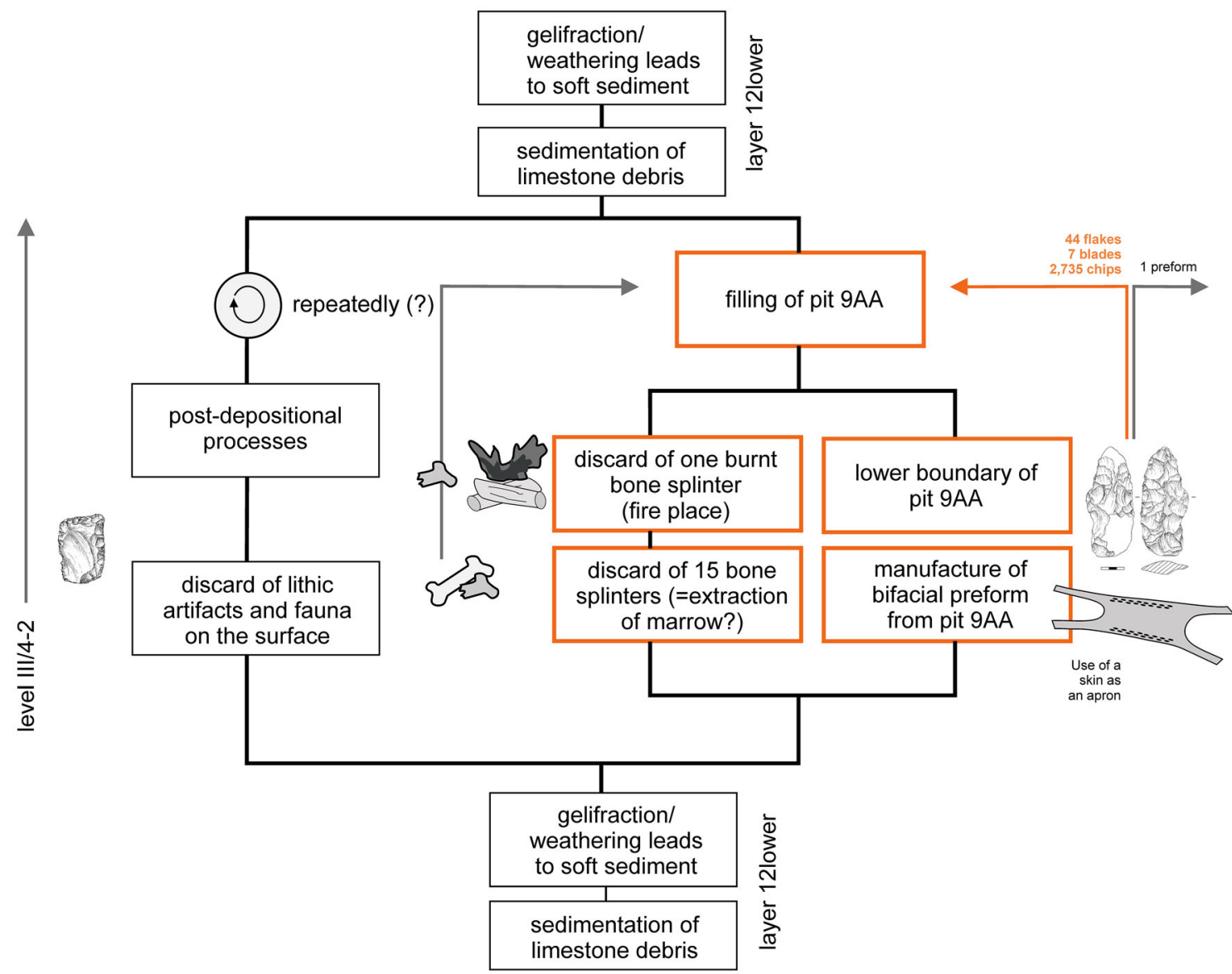

Fig. 11 Kabazi V, level III/4-2. Dendrogram of the chronological relationships among different site formation processes; those deduced from pit 9AA are highlighted in orange. The time axis is from bottom to top

\section{Discussion}

Excavations at a number of Crimean Middle Paleolithic sites have reported anthropogenic pits. The absolute chronology currently available (Chabai and Uthmeier 2006, 2018; Uthmeier 2012) suggests that sites with anthropogenic pits date to MIS 3 from approximately $50 \mathrm{ka}$ calBP to probably as late as $34 \mathrm{ka}$ calBP, although the later dates have been called into question (Péan et al. 2013). In all cases, the sites pertain to the Late Middle Paleolithic. The section that follows differentiates anthropogenic pits by formation process, distinguishing pits whose backfill stems from natural site formation processes from pits with anthropogenic backfill. The backfill of pits with artifacts is classified as originating from natural site formation processes when (1) find density is low and (2) the artifact composition is equal to the average artifact composition of the layer; a third, non-mandatory criterion is the fill consisting of several layers, pointing to a prolonged sedimentation. Conversely, the backfill of a pit is assumed to be intentional if (1) artifact density is high and (2) the sediments inside the pit are homogeneous, pointing to a rapid, for instance intentional, backfill. Considering such pits to be artifact depositions, we can distinguish further between (a) non-selective artifact assemblages that can be interpreted as the deposition of waste and (b) selective artifact assemblages, which are indicative of a function other than waste disposal.

\section{Anthropogenic pits with backfill from natural site formation processes}

At Kabazi V, level III/1 A, three anthropogenic deepened features were observed (Chabai and Veselsky 2007). However, judging by the processes of their formation, they appear to have had functions distinct those seen at level III/4-2 (Table 6). Whereas one pit was devoid of artifacts, two others contained artifacts. In contrast to pit 9AA from level III/4-2, the composition of the artifact classes found in these pits correlates well with that of the assemblage from the surface of the level, which already constitutes an argument against a deliberate choice of items and thus against intentional deposition. In addition, the density of artifacts within the filling of the pits is low, and the fills show a layering indicating slow sedimentation, which again contradicts the hypothesis of intentional deposition. It is apparent natural post-depositional processes transported the sediment and the artifacts into the pits, which, subsequently to their human use, functioned as a sedimentary 
Table 6 Kabazi V. Comparison of the main characteristics of anthropogenic pits. Pits from level III/1A are characterized by the sedimentary discontinuity of the filling and an artifact assemblage similar to that from the corresponding surface; the suggestion is therefore that these pits were not intentionally backfilled by human agents

\begin{tabular}{llll}
\hline & Level III/1A & & Level III/4-2 \\
\hline Pit & sq. $7 \mathrm{~A}$ & sq. $7 \mathrm{~B}$ & sq. 9AA \\
Diameter of pit & $49 \mathrm{~cm}$ & $37 \mathrm{~cm} \times 32 \mathrm{~cm}$ & $29 \mathrm{~cm} \times 18 \mathrm{~cm}$ \\
Depth of pit & $18 \mathrm{~cm}$ & $11 \mathrm{~cm}$ & $7 \mathrm{~cm}$ \\
Walls of pit & Abrupt & Abrupt & Semi-abrupt \\
Stratigraphy of pit fill & 3 layers & Sooty layer on top & Homogeneous \\
$N$ artifacts & 290 & 52 & 2786 \\
Chips & $92.1 \%$ & $69.2 \%$ & $98.1 \%$ \\
Flakes & $4.6 \%$ & $1.9 \%$ & $1.5 \%$ \\
Blades & $1.7 \%$ & $0.0 \%$ & $0.3 \%$ \\
Tools & $1.1 \%$ & $1.9 \%$ & $0.0 \%$ \\
Other (pebbles, bones) & 0.4 & $28.8 \%$ & $0.0 \%$ \\
Difference to finds from & No & No & Yes $(+$ no refits with \\
$\quad$ layer in the same square & & & artifacts from layer) \\
Formation process & Artificial pit => sedimentary trap & Artificial pit =>sedimentary trap & Artificial pit \\
Anthropogenic agency & Trampling & Trampling & Intentional deposition \\
\hline
\end{tabular}

trap; the only human agency that cannot be totally excluded is trampling. A number of anthropogenic pits from other Crimean Middle Paleolithic sites show comparable attributes and are also consistent with an explanation of the filling as a sedimentological trap. A series of pits unearthed at Zaskalnaya VI, cultural layer IV (Kolosov 1986, p. 52), are comparable in size and shape to those from Kabazi V, and the artifact content of the filling again did not differ from that of the corresponding layer. The same applies to an ovoid pit with a U-shaped profile from Chokurcha I, level IV-B, square 225, which had a length of $28 \mathrm{~cm}$, a width of $9 \mathrm{~cm}$, and a depth of $14 \mathrm{~cm}$ (Chabai 2004b, pp. 349-350). Finally, Bonch-Osmolowski documented several pits during his pioneering excavations at Kiik Koba (Bonch-Osmolowski 1940; Uthmeier 2013). In the upper cultural layer, he found a total of six pits, which he classified as anthropogenic on the basis of a list of attributes similar to the definitions used in this article. Three pits had abrupt walls and were of ovoid, rectangular, and rounded shape respectively (Bonch-Osmolowski 1940, pp. 133-136). While one of these contained the buried remains of a child, all others were backfilled with sediment and material identical to that from the relevant archeological level. The dimensions of the pits range from 70 to $140 \mathrm{~cm}$ in length, from 80 to $100 \mathrm{~cm}$ in width, and from 38 to $70 \mathrm{~cm}$ in depth. Three other large pits had slightly sloping walls but were classified as anthropogenic pits due to the presence of small spoil heaps regarded as the dug-out material. One was ovoid in shape, and two were round. The diameters of these pits range from 100 to $150 \mathrm{~cm}$ and their depths between 10 and $20 \mathrm{~cm}$ (Bonch-Osmolowski 1940, p. 134). Except for the burial pit, it appears that all the pits described so far were not dug specifically for the purpose of burying their actual filling. If any human agency was involved, conceivable mechanisms may have been trampling and/or the situational removal of sediment and artifacts from the immediate surroundings in order to clear a small surface. The low densities of finds in the pits exclude the possibility of an intentional deposition of waste in a strict sense, for instance of previously collected material.

\section{Anthropogenic pits with intentional backfill}

The intentionality of its backfill and the high artifact density found links pit 9AA from Kabazi $\mathrm{V}$ to other pits from the Crimean Middle Paleolithic. At Zaskalnaya V, cultural layer III, a small pit of $18 \mathrm{~cm}$ in diameter and $3 \mathrm{~cm}$ in depth contained 84 unretouched flakes plus the chips produced from one yellowish flint nodule (Kolosov 1983, pp. 46-47); the core was missing. A rounded pit with a $\mathrm{V}$-shaped profile found at Zaskalnaya VI, cultural layer II (Kolosov 1986, p. 19; Fig. 4, 20-21), square 32A, measured $20 \mathrm{~cm}$ in diameter and $5 \mathrm{~cm}$ in depth and contained eight bifacial tools (Kolosov 1986, p. 19, Fig. 4). As at Kabazi V, level III/4-2, the pit was positioned near the back wall of the rock shelter.

\section{Pit size, pit placement, and selectivity of deposited artifacts}

Comparison of all anthropogenic pits for which data on size and volume are available (Fig. 12) shows a clear distinction between the very large and voluminous pits from Kiik Koba, upper cultural layer (Fig. 12: size class 1), and all other documented cases. The estimated volumes of the 
Fig. 12 Comparison of the size and the volume of anthropogenic pits in the Crimean Middle Paleolithic (a all anthropogenic pits; $\mathbf{b}$ enlarged cut out of pits smaller than size class 1 ). The diagram shows the width and length as $x y$-coordinates; pits with artifact depositions are marked in orange $(\mathrm{Kab} .=$ Kabazi, Zas. $=$ Zaskalnaya, Cho. $=$ Chokurcha, Kiik = Kiik Koba). The volume of a pit (calculated as the smallest circumscribing cube by calculating the product of width, length, and depth) is indicated by the surface size of the corresponding bubble (Kiik Koba, upper layer*: calculations are based on the minimum and maximum volumes from 3 pits with abrupt walls; Kiik Koba, upper layer**: calculations are based on the minimum and maximum volumes from 3 pits with heaps from the excavated material)

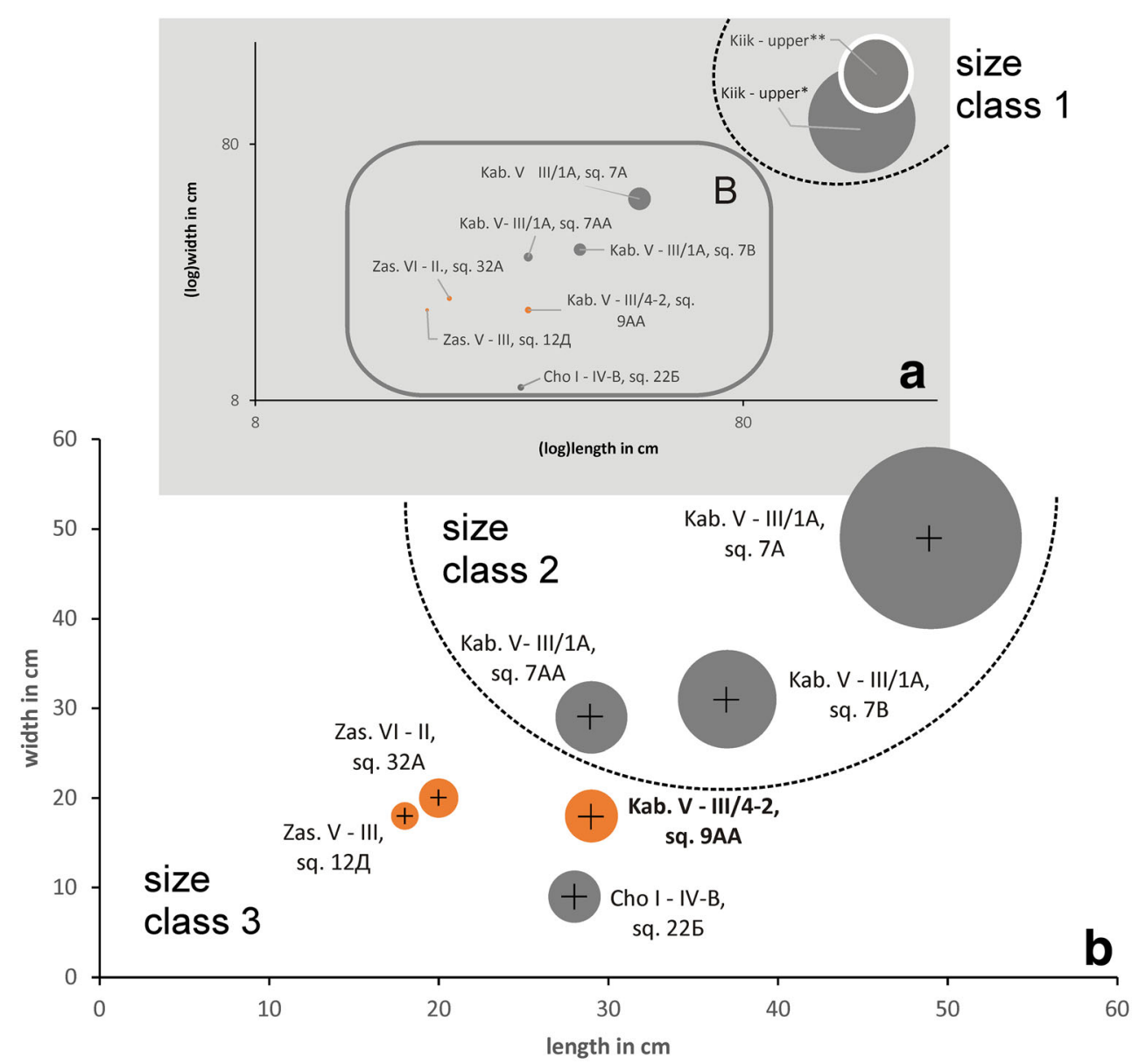

smallest circumscribing cube (calculated as the product of the length, width, and depth) of the pits from Kiik Koba, upper layer, are ten to twenty times larger than the volume of the largest pit from the other sites (Table 7). The marked differences in size point to differences in function and/or the contribution of agents other than humans. It seems appropriate to interpret the dispersed scatter of part of the human bones from the burial of an adult in the same layer as the result of a re-excavation (and enlargement) of the original burial pit, possibly by carnivores (Uthmeier 2013). This explanation would be in line with the low sedimentation rates postulated by Bonch-Osmolowski and may indicate a complex formation process involving human agency followed by animal activities. However, there are also differences within the remaining size classes (Fig. 12: size classes 2 and 3 ). With the exception of the equally small

Table 7 Comparison of the basic measurements of anthropogenic pits from the Middle Paleolithic of the Crimea (Kab. = Kabazi, Zas. = Zaskalnaya, Cho. $=$ Chokurcha, Kiik = Kiik Koba)

\begin{tabular}{|c|c|c|c|c|c|}
\hline & Length in $\mathrm{cm}$ & Width in $\mathrm{cm}$ & Depth in $\mathrm{cm}$ & Volume in $\mathrm{cm}^{3}$ & Deposition \\
\hline Kab. V-III/1a, sq. 7A & 49 & 49 & 18 & 43,218 & \\
\hline Kab. V-III/1a, sq. 7B & 37 & 31 & 11 & 12,617 & \\
\hline Kab. V-III/1a, sq. 7AA & 29 & 29 & 8 & 6728 & \\
\hline Kab. V-III/4-2, sq. 9AA & 29 & 18 & 7 & 3654 & 2735 lithics \\
\hline Zas. V-III, sq. 12Д & 18 & 18 & 3 & 972 & 84 flakes and chips \\
\hline Zas. VI-II, sq. 32A & 20 & 20 & 5 & 2000 & 8 bifacial tools \\
\hline Cho I-IV-B, sq. 22Б & 28 & 9 & 14 & 3528 & \\
\hline Kiik-upper* & 140 & 100 & 70 & 980,000 & \\
\hline Kiik-upper** & 150 & 150 & 20 & 450,000 & \\
\hline
\end{tabular}


pit from Chokurcha I, pits with deposited artifacts (Fig. 12: size class 3 ) tend to be smaller than pits with natural fillings (Fig. 12: size class 2), which underlines their function as receptacles. The data at hand do not permit an answer to the question of what function the pits of size class 2 had, but most probably it was a different one than the large pits of size class 1 . The case is different for pits of size class 3 that contained artifacts; in this case, which applies to three of the four smallest pits, the size of the pits corresponds to the total volume of the artifacts deposited. In addition, two pits (at Zaskalnaya VI, cultural layer II, and Kabazi V, level III/4-2) were located near the back wall of the rock shelter.

Summarizing, we propose that intentionally backfilled anthropogenic pits in the Crimean Middle Paleolithic are characterized by the following features:

- Artifact density is high.

- The backfill is anthropogenic.

- The size of the pit matches the volume of the deposited artifacts.

- The deposited artifacts represent a selection of the total variety of artifacts found in the corresponding level.

- In at least two cases, the pit was located near the back wall of the rock shelter.

The most salient attributes of Crimean Middle Paleolithic artifact depositions are the selection of the deposited items and their careful deposition in a feature exclusively created for this purpose. The remnant use index for the three pits with intentionally deposited lithics of size class 3 (Table 4) varies between RUI $=6.00$ as calculated for both Kabazi V, level III/42, and Zaskalnaya V, cultural layer III, and RUI $=45.00$ for Zaskalnaya VI, cultural layer II. In Zaskalanya VI, cultural layer II, the deposited pieces have comparably high remnant use not only due to the useful life of the existing working edges, but also due to their potential for rejuvenation, which the RUI does not express. By contrast, the remnant use of the flakes deposited in the pits in Zaskalanya V, cultural layer III, and at Kabazi V, level III/4-2, is much lower. At the same time, both pits contain chips, which are of low functional value.

It is difficult to identify the function of the artifact depositions, even on a broad level of "utilitarian" versus "nonutilitarain". What follows will discuss individually each of the principal hypotheses that might explain Crimean Middle Paleolithic artifact depositions, that is, caching, hideout, ritual, and waste. To guide the discussion, we awarded to the possible interpretations given in Fig. 4 qualitative parameter values relating to the factors "remnant use," "composition of artifacts," "spatial context," and "measures taken for retrieval", whose presence or absence in the Crimean Middle Paleolithic artifact depositions we tested for (Table 8). To give consideration to the partially inconclusive character of some of these factors, such as the variable remnant use of ritual depositions, we weighted them, with weightings ranging between 1 for uncertain factors and 2 for those of unambiguous character. To facilitate comparison, Table 8 contains a quotient of the actually achieved and the maximum possible score, whose purpose is to identify the best qualitative match between the data and the hypotheses for each interpretative variant.

\section{Artifact deposition in the Crimean Middle Paleolithic as waste disposal}

All artifact depositions discussed were deposited close to areas of activity, and two of them have a low remnant use. These characteristics match those defining the disposal of waste, but we need to note the exception represented by the relatively high remnant use of the deposited bifacial tools at Zaskalnaya VI, layer II. Similarly, several other aspects of all three pits are not in good accordance with an interpretation as waste disposal. First, although the rock shelter walls in each case and the slope in front of them place general limits on the area available for potential activities, all three sites are not of small scale in terms of the space under the roof and in front of the dripline. In addition, in the case of Kabazi V, level III/4-2, the low number of minimal individuals among the fauna hunted and the low artifact density found argue for an ephemeral, short-term use of the site. All this would seem to obviate the need for the sophisticated and prompt waste management suggested by size-adapted pits. A more ambiguous factor is the placement of two of the pits near the rock shelters' back wall, which could represent an intentional removal of the depositions from the main activity area or action designed to facilitate retrieval. However, simple removal of waste from the activity area would make more sense if it had been deposited without additional pits. The most convincing evidence against the waste disposal hypothesis is the selective character of the artifacts deposited. One would expect a deposition for waste disposal purposes to feature a random selection. This is certainly not the case for the bifacial tools from Zaskalanya VI. Given the logic intertwinement of waste management and more intensive occupations, it is also implausible to assume that the basic population for a random sample of waste would be limited to the reduction of one single raw nodule, as found at Kabazi V, level III/4-2, and Zaskalnaya V, layer III. The scores for the fit between the defining parameters for waste disposal and the presence of these attributes in the cases discussed above (Table 8) range between 0.29 and 0.43 . Deposition for waste disposal purposes is therefore unlikely in all three cases.

\section{Artifact depositions in the Crimean Middle Paleolithic as ritual depositions}

Most of the factors that define ritual deposition are rather unspecific (Table 8). Remnant use, the degree of selectivity in the artifact composition, and the presence or absence of measures to facilitate retrieval all allow for a range of value 
Table 8 Presence or absence of the elements of each interpretation considered for the artifact depositions from the Crimean Middle Paleolithic. The attributes were weighted between 1 (for uncertain attributes) and 2 (for those of unambiguous character) and used to calculate a score for the plausibility of each hypothesis by dividing the sum of the weighted attributes present in each case study by the maximum score $(0=$ no attributes present, $1=$ all attributes present $)$

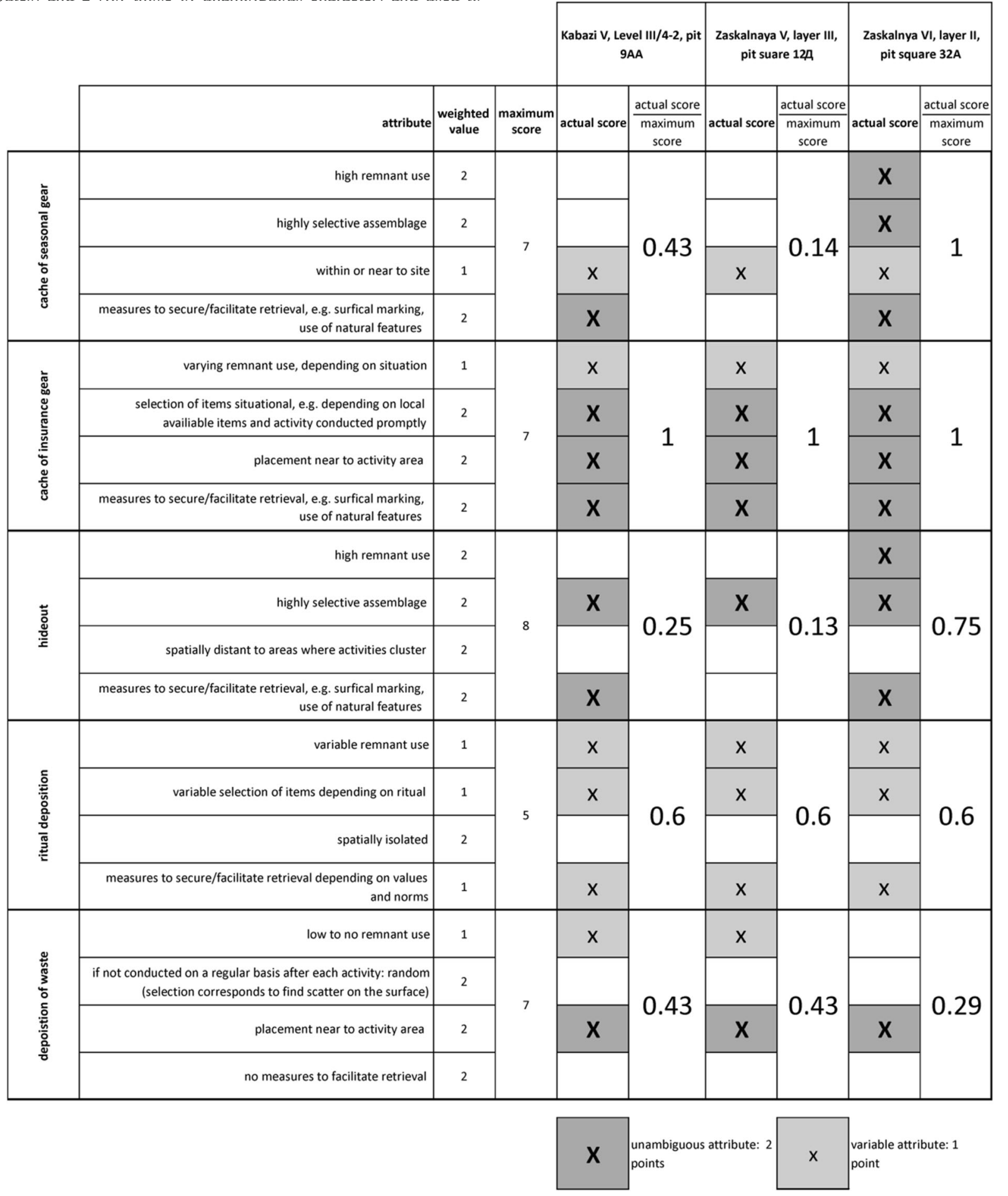

parameters. These attributes show definition in the Crimean deposits, but their lack of specificity causes overlap with other explanatory hypotheses. The requirement for spatial isolation is equally problematic due to its deduction from the topographical position of Paleolithic deposits characterized by highly selective assemblages and high workload (Tabarev 
et al. 2013; Kilby 2018). In other contexts, such as the PrePottery Neolithic (Hughes 2014), ritual depositions are often found within settlements and main activity areas. The fact that the Crimean Middle Paleolithic artifact depositions are rare in the overall Crimean Middle Paleolithic record, and thus represent an extraordinary class of features, would fit with their interpretation as ritual in nature; their containing mundane objects does not conflict with this interpretation. A criterion for a classification as ritual deposition that remains unmet is that of the assemblage's composition showing a formalized and repetitive character (Hughes 2014). Admittedly, the low number of cases limits the informational value of an internal comparison. Nevertheless, the Crimean depositions do not present us with enough evidence to identify a clear pattern: Kabazi II, level III/4-2, and Zaskalanya V, layer III, both consist of blanks with low remnant use stemming from the reduction of one nodule, whereas the bifacial tools deposited at Zaskalanya VI, layer II, represent products with high remnant use. Ritual deposition is thus unlikely for all three Crimean depositions, a conclusion also reflected in the fit scores of 0.6 (Table 8).

\section{Artifact depositions in the Crimean Middle Paleolithic for hideout purposes}

The artifact deposition from Zaskalanya VI, layer II, meets a number of formal requirements for interpretation as a hideout. The remnant use is reasonably high, artifact composition is restricted to one tool type-bifacial tools_- and the pit was located close to the back wall, probably to facilitate the deposition's retrieval. The concordance score for this hypothesis is 0.75 (Table 8), that is, two-thirds of the required attributes are present. The two other deposits lack several attributes of hideouts and have lower scores, of 0.13 and 0.25 respectively (Table 8). It seems beyond doubt that any economic rationale to hide the artifacts in these pits would conflict with the low remnant use and workload found for each deposited piece. However, it is noteworthy that both in pit 9AA in Kabazi V, level III/4-2, and in Zaskalnaya V, layer III, the totality of the lithic leftovers from the reduction of a single nodule was deposited into the pits. Is it possible that the artifact depositions were independent of the objects' material value and intended to hide the presence of the makers of deposited artifacts to later visitors to the site?

One argument supporting this supposition would be marked differences in raw material and/or technological features of the items deposited in comparison to the assemblage retrieved from the corresponding surface. However, the palimpsest character of the assemblages stands in the way of any assessment of technological differences. With regard to the raw material used, it is important to stress that both sites are located close to primary raw material sources (Chabai and
Uthmeier 2006, Fig. 18.1). The lithic assemblage at Kabazi V is dominated by Cretaceous flint from the nearby Mount Milnaya. The basic color of the fracture planes is gray, varying between light gray, brownish-gray, and dark gray, with varying frequencies of white to gray inclusions. There are no marked differences between the lithic content of the pit and the artifacts from the remaining assemblage, which is in part patinated. At Zaskalanya V, layer III, the lithic artifacts are mainly made on gray to black flint plaquettes originally embedded in chalk or marl deposits (Chabai and Uthmeier 2018). The nearest known outcrops are the bed of the Bijuk Karasu River, some $500 \mathrm{~m}$ from the site, and primary outcrops near the Middle Paleolithic site of Sary Kaya, approximately $2.5 \mathrm{~km}$ from Zaskalnaya V. The yellowish flint nodule described by Kolosov (1983, pp. 46-47) for the artifacts from the pit in layer III is indeed different from the rest of the assemblage.

There are multiple, and predictably potentially conflictive, criteria for interpreting a deposition as a hideout with the purpose of preventing others from recognizing that the deposition's maker had been at the site previously. Such a scenario is highly unlikely in relation to mobile hunter-gatherers. In general, the probability of intergroup conflicts among hunter-gatherers increases when territories are established and defended (Dyson-Hudson and Smith 1978). Small hunter-gatherer groups living in large territories defend them via social boundary defense (Dillian 2003), that is, the establishment of a system of values, norms, and social sanctions accepted by both insiders and outsiders. Actual spatial control of these boundaries is patchy, and the imposition of sanctions can only ensue when a violation is actually encountered. Assuming that the probability of detection is low, and depending on the positive effects of unauthorized access to a foreign territory, disregarding territorial boundaries may have been a positively evaluated option. The intensity of site use over time at Kabazi Mountain (Chabai and Uthmeier 2006) is indicative of the general importance of the surrounding landscapes to hunter-gatherer survival. It is therefore theoretically imaginable that an outsider surveying the hunting territory of another group at Kabazi Mountain for resources would try to hide his or her presence by depositing the debris from the manufacture of a spontaneously required piece of gear in a pit. Evidence confirming the establishment of territories, however, is lacking. All faunal remains from level III/4 reveal low minimum numbers of individuals and some indications of scavenging, which points to a low predictability of food resources and therefore argues against the establishment of socially defended territories during the period in question. A hideout function of the Crimean depositions in the context of intragroup conflict therefore appears highly unlikely. 
Artifact depositions in the Crimean Middle Paleolithic as caches

One principal utilitarian function of depositions in huntergatherer groups is that of caching gear for anticipated future demand. In his seminal study of the Nunamiut subsistencesettlement system, Binford (1978, p. 256) observed that hunter-gatherer groups apply a strategy of storage and caching not only to food, but also to gear. Passive gear is in storage, and active gear is in use. There is further categorization of gear that is not in active use into "seasonal gear," cached on a seasonal basis and regularly reused, and "insurance gear," cached for unforeseen emergency situations. Seasonal gear is usually of high quality and principally includes items with a long useful life and high potential for curation. To ensure relocation, seasonal gear is often cached at repeatedly occupied residential camps. Seasonal gear may also be the result of production in interrupted stages, preferably continued at the same residential camp or hunting stand during "dead time". "Insurance gear", by contrast, is often expedient in character and consists of immediately available materials. In general, the production and deposition of insurance gear are embedded in other activities and therefore of low direct cost (for procurement and caching) and low opportunity cost (the cost of the diversion of time and labor from alternative activities). The three artifact depositions discussed here show all attributes of insurance gear (Table 8 ): their varying remnant use, artifact selection explainable by situational circumstances (e.g., the flaking of a single nodule), their placement close to activity areas (in this case, the main find scatter), and placement near the back wall to facilitate retrieval. The score for the fit between defining factors and actual data is 1.00 in each case (Table 8). It is true that the deposition at Zaskalanya VI, layer III, shows a highly selective assemblage of eight bifacial tools and the highest remnant use of all three depositions. However, the low workload associated with lithics compared to artifacts made of other organic materials such as spears (Veil 1990a; 1990b), their low weight, and the local availability of the raw material all conflict with an interpretation as seasonal gear. Consequently, we classify the depositions from Kabazi V, level III/4-2, pit 9AA, Zaskalanya V, cultural layer III, and Zaskalnaya VI, cultural layer II, as caches for insurance gear.

Another defining factor for the placement of insurance gear in a pit is a high probability of retrieval. Excepting Kabazi II, Sary Kaya, Krasnaya Balka and Karabai, all Crimean Middle Paleolithic sites are rock shelters (Chabai and Uthmeier 2006). Despite the soft nummulitic limestone, the sedimentation rate is low, calculated at $0.19 \mathrm{~mm}$ per year for Kabazi V (Uthmeier and Chabai 2018). This means that within a 30 -year generation, the thickness of the sediment cover on top of the pit would be little more than $5 \mathrm{~mm}$. Some rock shelters, such as Zaskalnaya V and VI, have large openings which allow eolian and colluvial sediments to accumulate, including behind the dripline. But even if we take the average sedimentation rate for loess in Central Europe (without erosional loss) of $1 \mathrm{~mm}$ per year (Kukal 1990, p. 102) as a proxy for the sedimentation rate here, sediment cover after 30 years would be $3 \mathrm{~cm}$ only. On the other hand, a low sedimentation rate would mean that artifacts discarded on the surface during previous stays would also be visible for longer periods. A scenario which would fit with both the low sedimentation rate and the caching of objects in pits would be an initial phase of the occupation of the surface of level III/4-2. Such a scenario is not provable, but seems plausible at least for the two cases in which only the blanks and chips from a single nodule were put into the cache. It is highly probable that at least the surrounding area where the flaking took place had not yet been used; if it had been, one would expect at least a minimal degree of mixing in the pit fill with blanks from other nodules.

\section{Conclusion}

Evident anthropogenic features are a frequent phenomenon in the Crimean Middle Paleolithic. Apart from fireplaces at ground level or in anthropogenic pits or natural depressions, there are numerous anthropogenic pits that had a range of functions and which fall into three major classes in accordance with their size, the composition of their filling, and their overall formation process. The extent to which animal activities subsequent to human use altered the size and shape of the extremely large pits at Kiik Koba is unclear. The possibility that animal scavengers opened up storage or waste disposal pits filled with animal tissue, meat, and/or bones cannot be excluded. Several smaller pits with maximum diameters of $50 \mathrm{~cm}$ have retained their original anthropogenic shape. In most cases, their primary function is difficult to ascertain because their filling results from natural sedimentation processes and is thus unrelated to human use. This is not the case for a total of three anthropogenic pits from Zaskalnaya $\mathrm{V}$, Zaskalnaya VI, and Kabazi V. These pits are the smallest in the record, and their sizes and shapes correspond to the volume of the artifacts from the fill. The selection of the artifacts deposited in them is either of situational character (in this instance, the outcome of one reduction sequence) or related to a specific tool type (in this instance, bifacial tools). The position of two of the three pits near the back wall of a rock shelter indicates their makers' intention to facilitate rediscovery. The anticipated reuse, the variable remnant use, and the pits' placement close to activity zones corroborate the hypothesis of a caching function for the pits. The generally lower remnant use and essentially lower workload of lithic items in comparison to artifacts made from organic raw materials (Veil 1990a) point, in all these three cases, to these caches containing insurance rather than seasonal gear. The most plausible 
scenario for the deposition of lithic artifacts at a site with an artifact scatter excavated on the same surface is that of an initial phase of recurrent occupations, when the bulk of finds was not yet discarded. Such a scenario is in good accordance to the palimpsest character of most Crimean Middle Paleolithic assemblages explained by multiple, in part seasonally different site use within short periods (Chabai and PatouMathis 2006).

According to Binford (1978, p. 261), insurance gear is situational, because its production is opportunistic and its reuse is not precisely planned; it serves as a broad "backup strategy" for future emergency situations. The caching of insurance gear takes place wherever it is anticipated to be of potential future use. In the case of the Nunamiut, there is wide sharing of knowledge around locating caches of insurance gear, with a temporal depth of several generations through storytelling (Binford 1978, p. 257). The general consideration of caching as associated with a high degree of anticipation of future activities and risks entails its frequent equation with logistical subsistence patterns. There is considerable indication of planning depth in the Crimean Middle Paleolithic in the form of long-distance raw material transportation (e.g., at Prolom II: Chabai and Uthmeier 2006). The existence of kill-andbutchering sites for family herds of horses and thus the production of large bulk consumed elsewhere has been taken as evidence for storage and logistical subsistence patterns (Uthmeier and Chabai 2010). Recurrent identified instances of opportunistic hunting and scavenging led to the hypothesis that logistical patterns may have been related to seasons of abundance only (Uthmeier 2013). Regardless of their assumed function, Crimean sites fit into the general pattern observed for Middle Paleolithic sites in Europe (Turq et al. 2013). As elsewhere, any investment in evident features is low and distinct activity zones are rare. Most lithic assemblages are difficult to evaluate because excavations cover only part of the associated occupied areas, but in most cases, the high densities of finds result from the excellent preservation of chips rather than high frequencies of cores and tools. In any case, it is a frequent conclusion in this context that the lithic assemblages stem from several occupations (Chabai and Patou-Mathis 2006; Uthmeier and Chabai 2018). This, combined with the observation that many reduction sequences take place in discrete spatial and temporal segments (Chabai and Uthmeier 2006) and lithic raw material is mainly of local to regional provenance, fits in with the overall picture proposed by Turq et al. (2013) of highly mobile family groups that occupied small annual territories. This would have required recurrent returns to previous sites, which, in combination with logistical features in associated subsistence patterns, corroborates the interpretation of the Crimean Middle
Paleolithic artifact depositions discussed here as caches for insurance gear.

Acknowledgments The article was made possible by the kind invitation of Javier Baena, Julià Maroto, Florent Rivals, and Manuel Vaquero as the organizers of Session XVI-7 "Is 'Neanderthal behaviour' a useful concept? Multiscalar approches to the behavioural diversity of Middle Palaeolithic Neanderthal populations" at the 18th IUPPS World Congress held in Paris in June 2018. The analyses reported here were conducted in the frames of the German Science Foundation project "The dispersal of modern humans into an Eastern European refugial area of late Neanderthals: interdisciplinary studies of contemporaneous industries from the Middle to Upper Paleolithic transition in the Crimea (Ukraine)" (UT 41/2-1) and a research stipend provided for V. P. Chabai by the Humboldt Society in 2016. The authors would like to thank three anonymous reviewers, who helped to largely improve a first version of this article.

Funding Information Open Access funding provided by Projekt DEAL.

Open Access This article is licensed under a Creative Commons Attribution 4.0 International License, which permits use, sharing, adaptation, distribution and reproduction in any medium or format, as long as you give appropriate credit to the original author(s) and the source, provide a link to the Creative Commons licence, and indicate if changes were made. The images or other third party material in this article are included in the article's Creative Commons licence, unless indicated otherwise in a credit line to the material. If material is not included in the article's Creative Commons licence and your intended use is not permitted by statutory regulation or exceeds the permitted use, you will need to obtain permission directly from the copyright holder. To view a copy of this licence, visit http://creativecommons.org/licenses/by/4.0/.

\section{References}

Aubry T, Almeida M, Neves MJ, Walter B (2003a) Solutrean laurel leaf point production and raw material procurement during Last Glacial Maximum in Southern Europe: two examples from Central France and Portugal. In: Soressi M, Dibble HL (eds) Multiple approaches to the study of bifacial technologies. University of Pennsylvania, Philadelphia, pp 165-182

Aubry T, Peyrouse JB, Walter B (2003b) Les feuilles de laurier de Volgu (Saône-et-Loire): une énigme en partie résolue? Paléo 15:245-250

Bader ON, Bader NO (1979) Volchi Grot, some results of investigations. In: Kolosov YG (ed) The investigation of the Paleolithic in Crimea. Naukova Dumka, Kiev, pp 15-33 (in Russian)

Bailey G (2007) Time perspectives, palimpsests and the archaeology of time. J Anthropol Archaeol 26:198-223

Bataille G (2017) Neanderthals of Crimea - creative generalists of the Late Middle Palaeolithic. Contextualizing the leaf point industry Buran-Kaya III, Level C. Quat Int 435:211-236

Binford L (1978) Organization and formation processes: looking at curated technologies. J Anthropol Res 35(3):255-273

Boëda É (1995) Steinartefakt-Produktionssequenzen im Micoquien der Kulna-Höhle. Quartär 45(46):75-98

Bonch-Osmolowski GA (1940) Kiik-Koba Cave. Paleolithic of the Crimea Vol. 1. Moscow (In Russian)

Bosinski G (1967) Die mittlepaläolithischen Funde im westlichen Mittleuropa. Fundamenta A/4. Böhlau Verlag, Köln-Graz

Broglio A, Giacobini G, Peresani M, Bertola S, Cilli C, De Stefani M, Gurioli F (2005) L'abitato aurignaziano. In: Broglio A, Dalmeri G (eds) Pitture paleolitiche nelle Prealpi Venete: Grotta di Fumane e Riparo Dalmeri. Memorie Museo Civico di Storia Naturale di 
Verona, II serie, Sezione Scienze dell'Uomo 9, Preistoria Alpina Special Issue:23-37

Chabai VP (1998) Kabazi II: introduction. In: Marks AE, Chabai VP (eds) The Middle Paleolithic of western Crimea, ERAUL 84, vol 1. Université de Liége, Liège, pp 167-200

Chabai VP (2004a) The Middle Paleolithic of Crimea. Slyakh, Simferopol (in Russian)

Chabai VP (2004b) Chokurcha I: introduction. In: Chabai VP, Monigal K, Marks AE (eds) The Middle Paleolithic and Early Upper Paleolithic of Eastern Crimea, ERAUL 104, vol 3. Université de Liège, Liège, pp 343-353

Chabai VP (2007) Kabazi V: the lithological and archaeological sequences. In: Chabai VP, Richter J, Uthmeier T (eds) Kabazi V: Interstratification of Micoquian and Levallois-Mousterian camp sites, part 1. Palaeolithic sites of Crimea, Vol. 3. Shlyakh Simferopol-Cologne, pp 1-26

Chabai VP, Demidenko YE (1998) The classification of flint artifacts. In: Marks AE, Chabai VP (eds) The Middle Paleolithic of western Crimea, ERAUL 84, vol 1. Université de Liége, Liège, pp 31-51

Chabai VP, Patou-Mathis M (2006) The patterns of fauna and raw material exploitation in Middle Paleolithic site Kabazi V, level III/2 (Crimea). In: Kulakovskaya L (ed) The European Middle Paleolithic: 30 years after Korolevo. Kiev, pp 123-141

Chabai VP, Uthmeier T (2006) Settlement systems in the Crimean Middle Palaeolithic. In: Chabai VP, Richter J, Uthmeier T (eds) Kabazi II: 70.000 years after the last interglacial, The Palaeolithic sites of Crimea Vol, vol 2. Shlyakh, Simferopol-Cologne, pp 297-359

Chabai VP, Uthmeier T (2018) New excavations at the Middle Paleolithic site Zaskalnaya V, Crimea: the 2012-2013 field seasons. A preliminary report. Quartär 64:27-71

Chabai VP, Veselsky A (2007) Kabazi V: hearths \& pits. Chabai VP, Richter J, Uthmeier T (eds) Kabazi V: interstratification of Micoquian and Levallois-Mousterian camp sites, part I. The Palaeolithic sites of Crimea Vol. 3. Shlyakh, Simferopol-Cologne, pp 27-50

Chabai VP, Richter J, Uthmeier T (eds) (2005) Kabazi II: last interglacial occupation, environment and subsistence. The Palaeolithic sites of Crimea Vol. 1. Shlyakh, Simferopol-Cologne

Chabai VP, Richter J, Uthmeier T (eds) (2006) Kabazi II: 70.000 years after the last interglacial. The Palaeolithic sites of Crimea Vol. 2. Shlyakh, Simferopol-Cologne

Chabai VP, Richter J, Uthmeier T (eds) (2007) Kabazi V: interstratification of Micoquian and Levallois-Mousterian camp sites, part I. The Palaeolithic sites of Crimea Vol. 3. Shlyakh, Simferopol-Cologne

Chabai VP, Richter J, Uthmeier T (eds) (2008) Kabazi V: interstratification of Micoquian and Levallois-Mousterian camp sites, part II. The Palaeolithic sites of Crimea Vol. 4. Shlyakh, Simferopol-Cologne

Chernysh AP (1965) The Lower and Middle Paleolithic of Dniester River Valley. Proceedings of the Commission of Quartenary Period Investigations, XXV. Nauka, Moscow (in Russian)

Clarkson C, Haslam M, Harris C (2015) When to retouch, haft, or discard? In: Goodale N, Andrefsky W (eds) Lithic technological systems and evolutionary theory. Cambridge University Press, Cambridge, pp 117-138

Conard NJ (1992) Tönchesberg and its position in the Paleolithic prehistory of northern Europe. Monographien des RGZM 20. Verlag des Römisch-Germanischen Zentralmuseums, Mainz

de Loecker D (2006) Beyond the site. The Saalian archaeological record at Maastricht-Belvédère (the Netherlands). Analecta Praehistorica Leidensia 35/36. Leiden University Press, Leiden

Dillian CDK (2003) An archaeological approach to territoriality and boundary defense among northern California hunter-gatherers. SES 63:123-140

Dodonov AE, Tschepalyga AL, Mikhailesku CD, Zhou LP, Markova A, Trubikhin VM, Simakova AN, Konikov EG (2000) Last-interglacial records from central Asia to the northern Black Sea: stratigraphy and correlation. Geol Mijnb 79:303-311

Dyson-Hudson A, Smith EA (1978) Human territoriality: an ecological reassessment. Am Anthropol 80:21-41

Ernst NL (1934) The quaternary site near the Chokurcha village in Crimea. Proceedings of the second international conference of the Association for Quaternary Investigations in Europe 5:184-206 (in Russian)

Ferring CR (1998) Kabazi V: introduction and excavations. In: Marks AE, Chabai VP (eds) The Middle Paleolithic of Western Crimea, ERAUL 84, vol 1. Université de Liège, Liège, pp 273-285

Formozov AA (1958) The cave site Starosele and its place in the Paleolithic. Materials and Investigations of the Archeology of the USSR No. 71. Moscow (in Russian)

Formozov AA (1959a) The investigations of the Stone Age in the Crimea in 1956. Proceedings of the Institute of the History of the Material Culture 73:39-47 (in Russian)

Formozov AA (1959b) The Mousterian site Kabazi in the Crimea. Soviet Archeology XXIX-XXX:143-158 (In Russian)

Frison GC (1974) The Casper site. Academic Press, New York

Galán AB, Domínguez-Rodrigo M (2014) Testing the efficiency of simple flakes, retouched flakes and small handaxes during butchery. Archaeometry 56:1054-1074

Geneste JM (1985) Analyse lithique d'industries moustèriennes du Périgord: une approche technologique du comportement des groupes humains au Paléolithique moyen. Thèse de doctorat, Université de Bordeaux I

Hahn J (1986) Kraft und Aggression. Die Botschaft der Eiszeitkunst im Aurignacien Süddeutschlands? Archaeologica Venatoria 7. Verlag Archaeologica Venatoria, Tübingen

Hahn J (1988) Die Geißenklösterle-Höhle im Achtal bei Blaubeuren I. Forschungen und Berichte zur Vor- und Frühgeschichte in BadenWürttemberg 26. Theiss Verlag, Stuttgart

Hammer Ø, Harper DAT, Ryan PD (2001) PAST: paleontological statistics software package for education and data analysis. Palaeontol Electron 4(1):9. http://palaeo-electronica.org/2001_1/past/issue1_ 01.htm

Hayden B (1979) Paleolithic reflections: lithic technology and ethnographic excavations among Australian Aborigines. Australian Institute of Aboriginal Studies, Canberra

Housley RA, Sanderson DCW, Burbidge CI, Richter D (2007) Luminescence Analyses (OSL and TL) and AMS Radiocarbon Determinations. In: Chabai VP, Richter J, Uthmeier T (eds) Kabazi $\mathrm{V}$ : Interstratification of Micoquian and Levallois-Mousterian camp sites, part 1. Palaeolithic sites of Crimea, Vol. 3. Shlyakh Simferopol-Cologne, pp 51-68

Huckell BB, Kilby JD (eds) (2014) Clovis caches: new discoveries and current research. University of New Mexico Press, Albuquqerque

Hughes EA (2014) Structured deposition and the interpretation of ritual in the Near Eastern Neolithic: a new methodology. Dissertation, University of Liverpool. https://pdfs.semanticscholar.org/8480/ 0a469c3bd5e043c57f06fa3afaa6a1f8a0a2.pdf. Accessed 19 July 2019

Jennings TA, Pevny CD, Dickens WA (2010) A biface and blade core efficiency experiment: implications for Early Paleoindian technological organization. J Archaeol Sci 37:2155-2164

Jöris O (2001) Der spätmittelpaläolithische Fundplatz Buhlen (Grabungen 1966-69). Stratigraphie Steinartefakte und Fauna des Oberen Fundplatzes. Universitatsforschungen zur Prahistorischen Archaologie 73. Habelt, Bonn

Key AJM, Lycett SJ (2014) Are bigger flakes always better? An experimental assessment of flake size variation on cutting efficiency and loading. J Archaeol Sci 41:140-146

Key AJM, Lycett SJ (2017a) Form and function in the Lower Palaeolithic: history, progress, and continued relevance. J Anthropol Sci 95:67-108 
Key AJM, Lycett SJ (2017b) Influence of handaxe size and shape on cutting efficiency: a large-scale experiment and morphometric analysis. J Archaeol Method Theory 22:514-541

Kilby D (2018) A North American perspective on the Volgu Biface Cache from Upper Paleolithic France and its relationship to the "Solutrean Hypothesis" for Clovis origins. Quat Int 515:197-207

Kolosov YG (1972) Shaitan-Koba, the Mousterian site in the Crimea. Naukova Dumka (in Ukrainian)

Kolosov YG (1979) A new Mousterian site in Prolom Cave. In: Kolosov YG (ed) Investigations of the Paleolithic in Crimea. Naukova dumka, Kiev, pp 157-171 (in Russian)

Kolosov YG (1983) The Mousterian sites of the Belogorsk district. Naukova Dumka, Kiev (in Russian)

Kolosov YG (1986) The Ak-Kaya Mousterian culture. Naukova Dumka, Kiev (in Russian)

Kolosov YG, Stepanchuk VN, Chabai VP (1993) The Early Paleolithic of Crimea. Naukova Dumka, Kiev (in Russian)

Kukal, Z (1990) How are rates of geological processes measured and expressed? Kukal Z (ed) The rate of geological processes. EarthScience Reviews 28(1-3) (Special Issue), pp. 10-258

Lemorini C, Venditti F, Assaf E, Parush Y, Barkai R, Gopher A (2014) The function of recycled lithic items at late Lower Paleolithic Qesem Cave, Israel: an overview of the use-wear data. Quat Int 361:103112

Liubin VP (1969) About the probability of artificial constructions in Kiik Koba rock-shelter. Soviet Archaeology 2:244-246 (in Russian)

Liubin VP (1970) The Early Paleolithic. The Stone Age on the territory of the USSR. Nauka, Moscow, pp 19-42 (in Russian)

Marks AE, Demidenko YE, Monigal K, Usik VI (1998) Starosele: the 1993-1995 excavations. In: Marks AE, Chabai VP (eds) The Middle Paleolithic of Western Crimea, ERAUL 84, vol 1. Université de Liège, Liège, pp 67-100

Marquer L, Lebreton V, Otto T, Valladas H, Haesaerts P, Messager E, Nuzhnyi D, Péan S (2012) Charcoal scarcity in Epigravettian settlements with mammoth bone dwellings: the taphonomic evidence from Mezhyrich (Ukraine). J Archaeol Sci 39:109-120

Merritt SR, Peters KD (2019) The impact of flake tool attributes and butcher experience on carcass processing time and efficiency during experimental butchery trials. Int J Osteoarchaeol 29:220-230

Monigal K (2004) The lithic assemblage from Buran-Kaya III level C. In: Chabai VP, Monigal K, Marks AE (eds) The Middle Paleolithic and Early Upper Paleolithic of Eastern Crimea, ERAUL 104, vol 3. Université de Liège, Liège, pp 57-77

Pastoors A (2001) Die mittelpaläolithische Freilandstation von SalzgitterLebenstedt: Genese der Fundstelle und Systematik der Steinbearbeitung. Salzgitter Forschungen 3. Archiv des Stadt Salzgitter, Salzgitter

Pastoors A, Tafelmaier Y, Weniger GC (2015) Quantification of late Pleistocene core configurations: application of the working stage analysis as estimation method for technological behavioural efficiency. Quartär 62:63-84

Patou-Mathis M (2007) Analyses Archéozoologiques des Unités III et IV de Kabazi V. In: Chabai VP, Richter J, Uthmeier T (eds) Kabazi V: interstratification of Micoquian and Levallois-Mousterian camp sites, Part I. Palaeolithic sites of Crimea, vol 3. SimferopolCologne, Shlyakh, pp 97-128

Péan S, Puaud S, Crépin L, Prat S, Quiles A, van der Plicht J, Valladas H, Stuart AJ, Drucker DG, Patou-Mathis M, Lanoë F, Yanevich A (2013) The Middle to Upper Paleolithic sequence of Buran-Kaya III (Crimea, Ukraine): new stratigraphic, paleoenvironmental, and chronological results. Radiocarbon 55(2-3):1454-1469

Peresani M (2009) The range of caching behavior among the past huntergatherers of Europe. In: Bonnardin S, Hamon C, Lauwers M, Quilliec B (eds) Du matériel au spirituel. Réalités archéologiques et historiques des « dépôts » de la Préhistoire à nos jours. XXIXe rencontres internationales d'archéologie et d'histoire d'Antibes. Éditions APDCA, Antibes, pp 87-95

Picin A (2016) Short-term occupations at the lakeshore: a technological reassessment of the open-air site Königsaue (Germany). Quartär 63: $7-32$

Pigeot N (1987) Magdaléniens d'Étoilles. Économie de débitage et organisation social. XXVe supplément à Gallia Préhistoire. Editions CNRS, Paris

Prasciunas MM (2007) Bifacial cores and flake production efficiency: an experimental test of technological assumptions. Am Anthropol 72: 334-348

Richter J (1997) Sesselfelsgrotte III. Der G-Schichten-Komplex der Sesselfelsgrotte - Zum Verständnis des Micoquien. Saarbrücker Druckerei und Verlag, Saarbrücken

Riel-Salvatore J, Clark GA (2001) Grave markers: Middle and Early Upper Paleolithic burials and the use of chronotypology in contemporary Paleolithic research. Curr Anthropol 42(4):449-479

Riel-Salvatore J, Gravel-Miguel C (2013) Upper Palaeolithic mortuary practices in Eurasia. A critical look at the burial record, The Oxford handbook of the archaeology of death and burial. Oxford University Press, Oxford, pp 303-346

Rigaud JP (ed) (1988) La Grotte Vaufrey. Paléoenvironnement, Chronologie, activités humaines. Mémoires de la Societé Préhistorique Française XIX. CNRS, Paris

Roebroeks W (1988) From find scatters to early hominid behaviour. A study of Middle Palaeolithic riverside settlements at MaastrichtBelvédère (the Netherlands). Analecta Praehistorica Leidensia 21. Leiden University Press, Leiden

Ryan WBF, Candace MO, Gilles O, Goldstein SL (2003) Catastrophic flooding of the Black Sea. Annu Rev Earth Planet Sci 31:525-554

Sauer F (2018) Spätpaläolithische Landnutzungsmuster in Bayern. PhD Dissertation, FAU Erlangen-Nürnberg. https://opus4.kobv.de/ opus4-fau/frontdoor/index/index/docId/9287. Accessed 22 July 2019

Schick K, Toth N (1993) Making silent stones speak. Simon and Schuster, New York

Schild R (2005) The killing fields of Zwolen. A Middle Paleolithic killbutchery site in Central Europe. Institute of Archaeology and Ethnology of the Polish Academy of Sciences, Warsaw

Sensburg M (2007) Die räumliche Organisation der Konzentration IIa von Gönnersdorf. Struktur und Dynamik eines magdalénienzeitlichen Siedlungsbefundes am Mittelrhein. Monographien des Römisch-Germanischen Zentralmuseums 69. Verlag des Römisch-Germanischen Zentralmuseums, Mainz

Shott MJ, Sillitoe P (2005) Use life and curation in New Guinea experimental used flakes. J Archaeol Sci 32:653-663

Soffer O (1985) The Upper Paleolithic of the central European plain. Academic Press, Orlando

Street M, Jöris O, Turner E (2012) Magdalenian settlement in the German Rhineland - an update. Quat Int 272-273:231-205

Tabarev AV, Gillam JC, Kanomata Y, Gunchinsuren B (2013) A Paleolithic cache at Tolbor (northern Mongolia). Archaeol Ethnol Anthropol Eurasia 41(3):14-21

Terberger T (1994) Pferdejäger und Muschelsammlerinnen. Ein altsteinzeitlicher Lagerplatz bei Wiesbaden Igstadt. Denkmalpflege in Hessen 1:44-47

Terberger T (1998) Siedlungsspuren zwischen 20.000 und 16.000 BP am Mittelrhein? Vorbericht zu den Ausgrabungen an der jungpaläolithischen Freilandstation Wiesbaden Igstadt, Hessen. Germania 76:403-437

Turq A, Roebroeks W, Bourguignon L, Faivre JP (2013) The fragmented character of Middle Palaeolithic stone tool technology. J Hum Evol 65:641-655

Uthmeier T (2012) The transition from Middle- to Upper Palaeolithic at Buran Kaya III, Crimea (Ukraine): a case of conceptual continuity of lithic artefact manufacture? In: Pastoors A, Peresani M (eds) Flakes 
not blades: the role of flake production at the onset of the Upper Palaeolithic, Wissenschaftliche Schriften des Neanderthal Museums, vol 5. Neanderthal Museum, Mettmann, pp 239-260

Uthmeier T (2013) From transformation analysis to land use pattern: the original assemblage of layer IV from Kiik-Koba grotto. In: Demidenko YE, Uthmeier T (eds) Kiik-Koba Grotto, Crimea (Ukraine): re-analysis of a key site of the Crimeqan Micoquian (Kölner Studien zur Prähistorischen Archäologie 3). Leidorf, Rahden, pp 129-160

Uthmeier T, Chabai VP (2010) Neanderthal subsistence tactics in the Crimean Micoquian. In Conard, NJ (ed) Settlement dynamics of the Middle Paleolithic and Middle Stone Age, Volume III, Kerns, Tübingen, pp 195-234

Uthmeier T, Chabai VP (2018) Formation processes at sites with high resolution sequences in the Crimean Middle Paleolithic: the Kabazi $\mathrm{V}$ rockshelter and the openair site of Kabazi II compared. Quat Int 485:44-67

Uthmeier T, Ickler S, Kurbjuhn M (2008) Site catchment analysis in the Late Crimea Middle Palaeolithic: a GIS based approach. In: Chabai VP, Richter J, Uthmeier, T (eds) Kabazi V: interstratification of Micoquian and Levallois-Mousterian camp sites, part II. The Palaeolithic sites of Crimea Vol. 4. Shlyakh, Simferopol-Cologne, pp 481-508

Valde-Nowak P, Nadachowski A, Wolsan M (1987) Upper Palaeolithic boomerang made of a mammoth tusk in south Poland. Nature 329: 436- 438

Verpoorte A (2012) Caching and retooling in Potocka Zikalka (Slovenia). Implications for late Aurignacian land use strategies. Archäologisches Korrespondenzblatt 42:135-151

Veil S (1990a) Die Nachbildung einer Jagdlanze der Neandertaler aus Lehringen. Ldkr Verden Archäologische Mitteilungen aus Nordwestdeutschland Beiheft 4:284-286

Veil S (1990b) Die Nachbildung der Lanze von Lehringen - Experimente zur Holzbearbeitung im Mittelpaläolithikum. Die Kunde. Neue Folge 41(42):9-22

Veil S, Breest K, Höfle HC, Meyer HH, Plisson H, Urban-Küttel B, Wagner GA, Zöller L (1994) Ein mittelpaläolithischer Fundplatz aus der Weichsel-Kaltzeit bei Lichtenberg. Lkr LüchowDannenberg Germania 72:1-66

Veselsky A (2008a) Kabazi V: production and rejuvenation of bifacial tools. In: Chabai VP, Richter J, Uthmeier T (eds) Kabazi V: interstratification of Micoquian and Levallois-Mousterian camp sites, part II, The Palaeolithic sites of Crimea Vol, vol 4. Shlyakh, Simferopol-Cologne, pp 455-480

Veselsky A (2008b) Kabazi V, sub-unit III/4: artefacts. In: Chabai VP, Richter J, Uthmeier, T (eds) Kabazi V: interstratification of Micoquian and Levallois-Mousterian camp sites, part II. The Palaeolithic sites of Crimea Vol. 4. Shlyakh, Simferopol-Cologne, pp 275-310

Weißmüller W (1995) Die Silexartefakte der Unteren Schichten der Sesselfelsgrotte. Ein Beitrag zum Problem des Moustérien. Sesselfelsgrotte II. Quartär-Bibliothek 6. Saarbrücker Druckerei und Verlag, Saarbrücken

Wiśniewski A, Lauer T, Chłoń M, Pyżewicz K, Weiss M, Badura J, Kalicki T, Zarzecka-Szubińska K (2019) Looking for provisioning places of shaped tools of the late Neanderthals: a study of a Micoquian open-air site, Pietraszyn 49a (southwestern Poland). Comptes Rendus Palevol 18:367-389

Wolf S, Conard NJ (2018) Personal ornaments of the Swabian Aurignacian. Palethnologie 7. http://journals.openedition.org/ palethnologie/897. Accessed 22 July 2019

Yevtushenko AI (1998a) Kabazi V: introduction and excavations. In: Marks AE, Chabai VP (eds) The Middle Paleolithic of Western Crimea, ERAUL 84, vol 1. Université de Liége, Liège, pp 273-286

Yevtushenko AI (1998b) Kabazi V: assemblages from selected levels. In: Marks AE, Chabai VP (eds) The Middle Paleolithic of Western Crimea, ERAUL 84, vol 1. Université de Liége, Liège, pp 287-322

Chabai VP, Richter J, Uthmeier Th, Yevtushenko AI (2002) Neue Forschungen zum Mittelpaläolithikum auf der Krim. Germania, 80: 441-473.

Publisher's note Springer Nature remains neutral with regard to jurisdictional claims in published maps and institutional affiliations. 